\title{
THEORY, CONSTRUCTION, AND USE OF THE PHOTOMETRIC INTEGRATING SPHERE
}

\author{
By E. B. Rosa and A. H. Taylor
}

ABSTRACI

Part I deals with the materials and construction of various spheres, and describes in detail the construction of a reinforced concrete sphere at the Bureau of Standards. It gives tests of the accuracy of integration by this sphere, the absorption of light by the sphere coating and by objects in the sphere, and the effect of the position of lamps. Proper methods of operation are also outlined.

Part II gives a fairly complete resume of the general theory of the sphere, with the addition of a considerable amount of new material, showing how to test the accuracy of the sphere, and how to improve the accuracy of integration. It also gives a bibliography of the subject.

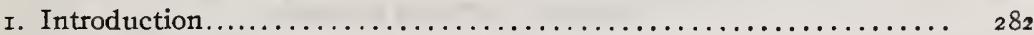

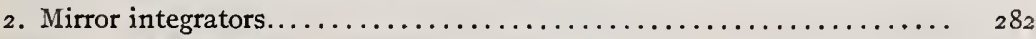

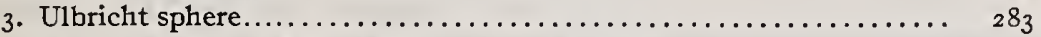

4. Materials of which spheres have been constructed.............. $28_{3}$

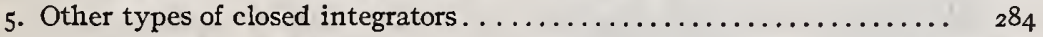

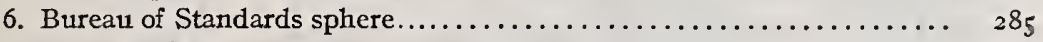

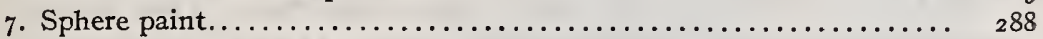

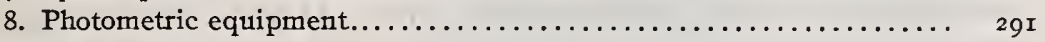

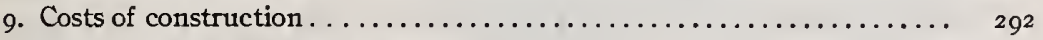

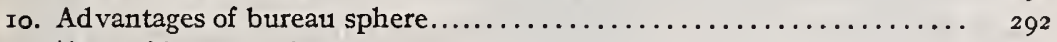

Ix. Tests of bureau sphere............................. 293

12. Absorption of reflected light by foreign objects............... 295

I3. Reflection factor of sphere coating .................... 296

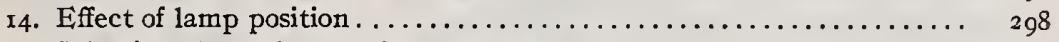

15. Selective absorption by the sphere surface................. 299

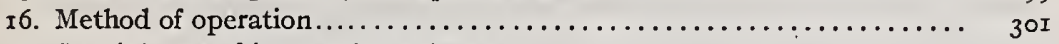

17. Special uses of integrating spheres................... 304

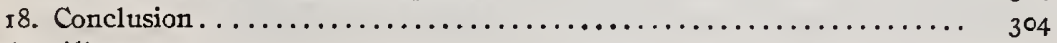

Part II: Theory . . . . . . . . . . . . . .

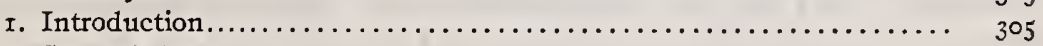

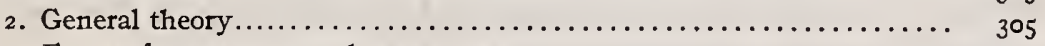

3. Errors of measurement due to screen.................... 307

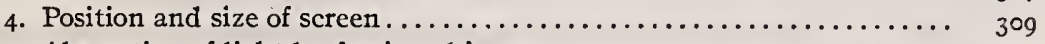

5. Absorption of light by foreign objects..................... 314

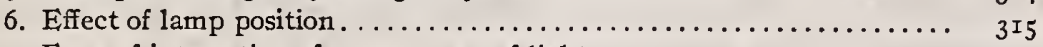

7. Error of integration of narrow cone of light............... 3 I 7

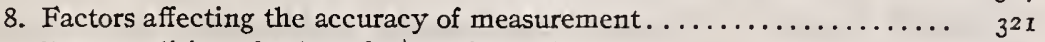

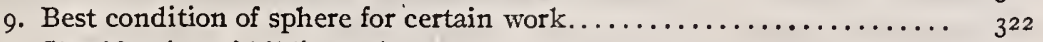

10. Classification of bibliography. . . . . . . . . .

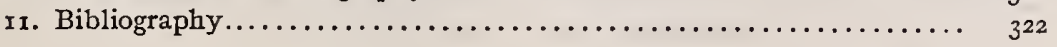




\section{PART I.-CONSTRUCTION AND USE}

[By E. B. Rosa and A. H. Taylor]

\section{INTRODUCTION}

In the early history of photometry, as in most of the sciences, the apparatus was somewhat crude and simple in design. For a long time there was no need for other than simple photometers, which measured the light intensity in a single direction. With the development of various types of arc lamps and other improved illuminants the need for another type of photometric measurement, the measurement of relative intensities in various directions, became apparent. During the past 25 or 30 years the science of illumination has grown very fast, on account of the great strides made in the production of improved illuminants. This is especially true for the last decade. Since the light distribution from the various illuminants is so different, the only true basis of comparison is in terms of total light output, measured in lumens or spherical candlepower.

\section{MIRROR INTEGRATORS}

Probably the first instrument designed to give the spherical candlepower with only one measurement was the "lumenmeter" of Blondel.*1 It consisted of a small hollow sphere with two vertical $18^{\circ}$ sectors on opposite sides removed. This sphere was placed on the axis of an ellipsoidal mirror, at such a point that the light from a lamp placed at the center of the sphere (which had a black interior surface) fell on the mirror through the open sectors, and was reflected to the photometer. The use of this "lumenmeter" apparently was limited to the measurement of axially symmetrical light sources.

Other types of integrators which employ mirrors to reflect the light to the photometer from definite angular positions about the source have been designed by Blondel, Matthews, Russell, and Leonard. As it is not the purpose of this paper to describe mirror integrators, those who are interested are referred to the original articles, listed in the bibliography, for further details.

A study of the operation of integrators utilizing the reflections from multiple mirrors makes evident the fact that very accurate adjustment of the mirrors is necessary, and since they can not be depended upon to remain unchanged indefinitely the delicate adjustments must be checked frequently. In addition to this

*1 References are given in bibliography on p. 322 . 
Scientific Papers of the Bureau of Standards, Vol. 18

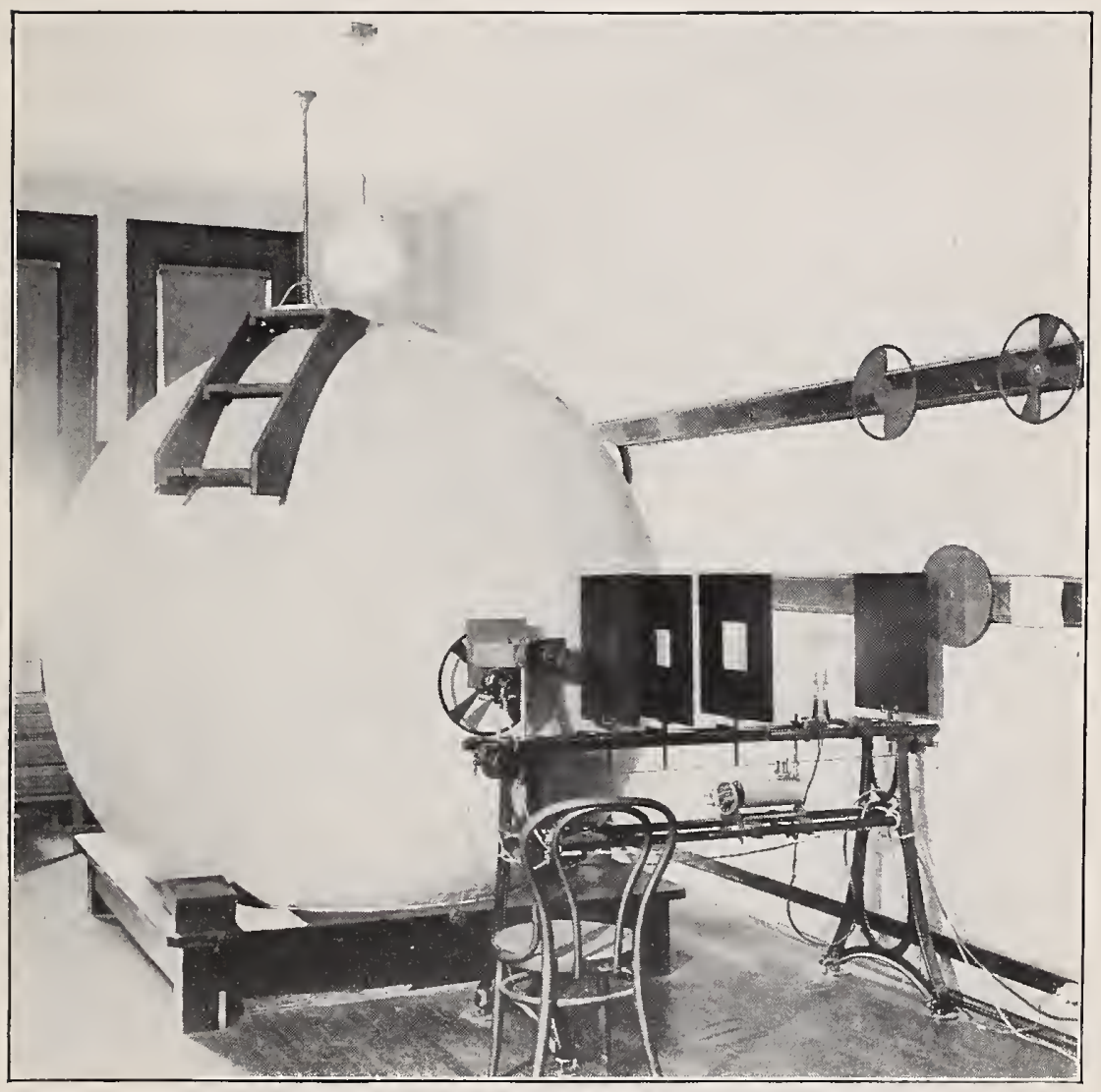

FIG. I.-General view of sphere and auxiliary equipment 
disadvantage, accurate integration of axially unsymmetrical light sources with such integrators is very difficult, if not impossible.

\section{ULBRICHT SPHERE}

In 1900 Ulbricht $^{8}$ proposed the use of a hollow sphere, with diffusely reflecting white walls, for light integration. His results and the investigations of others have shown that such a sphere, when properly designed and used, is capable of giving highly accurate results. Its great simplicity and usefulness have so strongly recommended it that it has superseded all other types of apparatus where it is desired to integrate the light flux from lamps.

Since the Ulbricht sphere has come into such general use, and is to be found in all well-equipped photometric laboratories of the present day, it has been thought desirable to give some structural details of spheres which have been described, as well as the methods which have been used in constructing a large sphere at the Bureau of Standards.

\section{MATERIALS OF WHICH SPHERES HAVE BEEN CONSTRUCTED}

The first sphere with which Ulbricht ${ }^{8}$ made his experiments was a milk-glass ball, $50 \mathrm{~cm}$ in diameter, with an opaque covering. On one side a portion of the wall was unobscured, and the transmitted light, passing through an opening $8 \mathrm{~cm}$ in diameter in an opaque screen, illuminated the photometer screen.

Blondel was one of the first to realize a practical construction of the Ulbricht sphere. His sphere was $83 \mathrm{~cm}$ in diameter, and made of sheet metal shaped into hemispheres on a mold.

The smaller sizes of spheres in use to-day are usually made of sheet metal shaped on molds by pressure or hammering, or of sectors of sheet metal fastened together by riveting or welding. The Edison Lamp Works, Harrison, N. J., has an excellent large sphere of the latter type, in which the sheet-iron sectors are electrically welded. It is divisible into hemispheres. Bloch ${ }^{18} \mathrm{de}-$ scribes a sphere made of zinc plate $2 \mathrm{~mm}$ thick, the two halves of the globe being built up by pressure on a model, and subsequently connected by suitable screws and wing nuts. The sizes larger than I $m$ diameter are usually made of sheet-metal segments fastened to structural steel or flat steel ribs. Such spheres have been described by Monasch ${ }^{13}$ and various other writers. Marchant ${ }^{29}$ has described a sphere, at the University of Liverpool, 5 feet 3 inches ( $1.6 \mathrm{~m}$ ) internal diameter, built of asbestos 
millboard one-fourth inch $(6 \mathrm{~mm})$ thick fastened to 46 five-eighthinch T-iron ribs, bent into circular arcs. It is made in halves, one of which is on rollers. Corsepius ${ }^{12}$ has described a sphere made of hair plaster, applied to a wire skeleton framework covered with gauze. Upon this plaster is a coat of plaster of Paris.

A fairly inexpensive spherical integrator can be made up by the use of a papier-mâché globe such as is used in instruction in geography.

\section{OTHER TYPES OF CLOSED INTEGRATORS}

Monasch ${ }^{13}$ has advocated the use of a large hemisphere with flat cover instead of a sphere for certain spherical candlepower measurements, on account of its lower cost and greater ease of manipulation. He described tests of a hemisphere of $2 \mathrm{~m}$ diameter which indicated that the illumination of the photometer window did not vary greatly when the lamp position was varied, the differences found being of the order of 2 per cent. This is too great a variation for precision work, however.

Sumpner ${ }^{26}$ has suggested the use of a rectangular box instead of a sphere on account of its simpler construction and lower cost. His article discusses the probable accuracy of such an integrator, but in the discussion several others disagreed with his conclusions. Details of the construction and use of cubical integrators have been described by other writers. Anyone interested is referred to the original literature. (See Bibliography.)

It seems doubtful that a cubical integrator would be very satisfactory where a higher accuracy than 2 to 4 per cent is desired for all types of light sources, but it might be quite useful where certain types of measurements were to be carried out, for example, change of efficiency of a gas lamp when the gas rate and air adjustment are changed. The box could be made to approach more nearly the spherical shape by blocking up the corners or filling them with cement. The principal advantage of the cubical integrator lies in its low cost and simplicity of construction. A thorough study of such an instrument by a laboratory equipped to carry out exhaustive tests would perhaps be of considerable value in showing the probable magnitude of the errors which might be encountered in service. The approach to spherical shape by blocking up the corners, which should be easy to accomplish, should be carried out in such an investigation. 


\section{BUREAU OF STANDARDS SPHERE}

During the summer of 1915 a reinforced concrete sphere, 88 inches $(2.23 \mathrm{~m})$ internal diameter, was built at the bureau. Since many details of its construction are unlike those of spheres

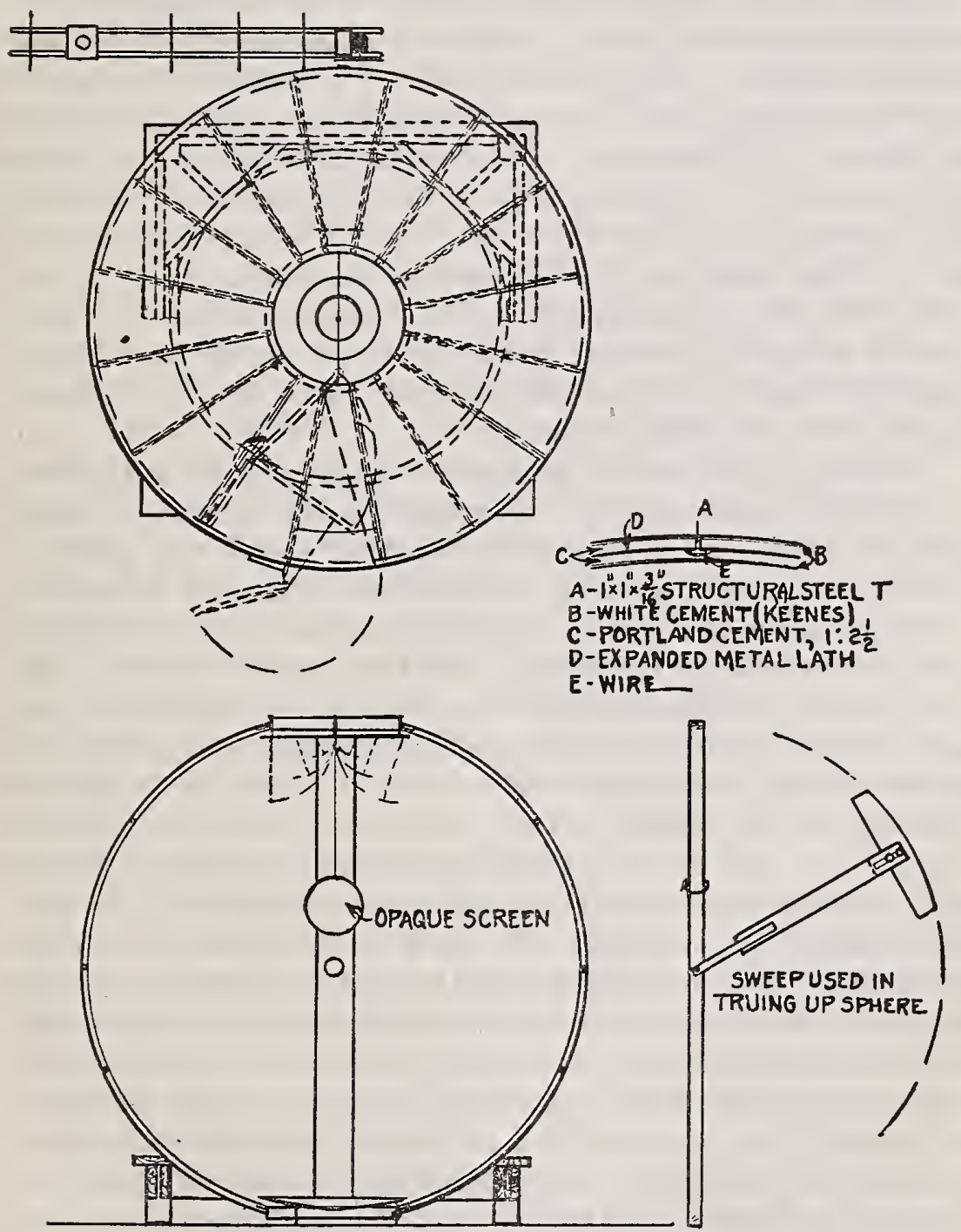

FIG. 2.-General plan of Bureau of Standards concrete sphere

previously described, it has seemed desirable to give a detailed description of it. The general plan of the sphere is shown in the sketches in Figure 2, while Figure I gives a general view of the sphere and its equipment. 
It has 16 vertical ribs of structural steel $T$, I by $\mathrm{I}$ by $1 / 8 \mathrm{inch}$. (The ribs would be better if three-sixteenths instead of oneeighth inch thick, as the latter have been found to be too flexible. Also, the structural framework should be supported above as well as below while putting on the expanded metal and applying the cement mortar and plaster, to prevent departure from the true spherical shape.) The ribs are fastened at top and bottom to steel rings, made up of 2 by $\mathrm{I} / 2$ inch angle iron, bent and welded in rings of 2 feet diameter. Between each pair of ribs are three steel straps of I by $1 / 4$ inch section, these being fastened with small bolts at each end to the top of the $T$, and butting up against its web. These strengthen the framework and make it rigid. Between the ribs are fastened sheets of expanded metal, such as is used in ordinary plastering work, cut to fit the spaces and fastened in place by wires passing over the top of the T's, as shown in the sectional sketch, Figure 2.

The body of the sphere is plastered inside and out with Portland cement mortar, of the proportions I part cement to $2 \mathrm{I} / 2$ parts of sand. This was applied to the expanded metal with a curved trowel, and swept out to a true spherical shape by a suitable sweep, as shown in Figure 2. The sweep was made up of a wooden circular arc fastened to an arm. Steel straps were bolted to this arm, and at the other end they were fastened by a horizontal bolt at the middle point of a 2 -inch pipe which passed through holes in boards forming bearings at the center of the top and bottom openings of the sphere. Hence the pipe could turn about a vertical axis, and the arm about a horizontal axis, thus allowing the sweep to reach all parts of the spherical surface. The pipe was threaded at both ends and fitted with lock nuts, so that a small adjustment up or down could be made. Provision was also made for a small adjustment of the length of the arm carrying the sweep. After sweeping, the cement surface was scratched, and when dry the walls were coated inside and outside with a mixture of Keene's "fine" cement, with Io per cent hydrated lime added. This gives a hard white surface which can be made as smooth as desired. It is difficult to obtain a pure white surface in this way, however, if a thin coating is used, as grains of the Portland cement work up to the surface in applying the white cement. In that case it is necessary to paint the surface later.

The bottom hole of the sphere is covered by a concave metal disk standing on three legs on the floor. This disk may be raised 
so that a space about $\mathrm{I}$ inch high is left for the admission of air when tests of gas or arc lamps are being made. The top hole is covered by a flat aluminum disk which may be let down from above far enough to allow an annular air space of about $\mathrm{I}$ inch. This disk is made up of annular rings, cut in half, and hinged so that any section can be let down, and any section can be entirely removed by drawing out the pin of the hinge. Button latches hold the sections up. By means of this arrangement lamps suspended from an overhead track can be lowered into the sphere after dropping down the proper center sections. If it is desired to have the lamp wholly in the sphere, these sections can be raised again, closing the opening except for a I-inch hole through which the lamp suspension and wires pass. If it is desired to have only the globe of an arc lamp inside the sphere, the proper center sections can be removed entirely, and, if the mechanism casing does not fill the hole, white paper can be used to complete it. The top opening of the sphere is easily accessible by means of a stepladder and a short ladder fastened on the side of the sphere.

On one side of the sphere is a hinged door 37 inches high and $16 \mathrm{~T} / 2$ inches wide at its widest point. When shut it forms part of a sector between two adjacent ribs. The hinges used are ordinary I6-inch strap hinges, bent to fit the curved surfaces to which they are fastened. The axes of the hinges are about 3 inches from the sphere surface and are braced by steel rods passing into the spherical shell. The rods have two nuts on the end passing through the hinge, so that it can be forced in either direction to take up sag due to the weight of the door.

While this method of adjustment has served satisfactorily to adjust such sags, some difficulty has resulted from the wear on the hinges which can not be compensated by this adjustment. These hinges carry a large weight and have to be opened and closed a great many times. It would be worth while to use specially constructed hinges with larger bearing surfaces, and the hinges should be kept well oiled.

In the wall diametrically opposite the door, on the equator, is a brass tube about $3 \frac{1}{8}$ inches in diameter. In 20 this telescopes another tube which carries the milk-glass window, with proper diaphragms for screening it. The milk glass is flush with the inner surface of the sphere when in use, but can be removed for cleaning. A second thin milk-glass window, carried at the end of another telescoping tube, is outside of this window. Its $100904^{\circ}-22-2$ 
use enables the operator to vary the intensity of the observation window through a limited range without a material change in the color of the light. It is much smaller than the other window, being only a little larger than the field of view of the photometer. It has been found to be very useful in practical operation of the sphere.

At a point about 27 inches in front of the window are two vertical rods upon which a runner may be moved up or down by a string passing through a small tube in the wall directly above. Four screens of diameters II, 2I, 30, and $38 \mathrm{~cm}$ are provided to be attached to the runner, one at a time, so that for any lamp the smallest screen usable can be chosen.

The method of introducing the lamp socket into the sphere is unlike any heretofore described. At a point to the left of the door, just above the equator, a section of one-half-inch conduit passes into the sphere horizontally to a distance of $13 \frac{1}{2}$ inches, at which point another section about 23 inches long is hinged to it. At the end of this section are two lamp sockets, one above the other, so that lamps can be burned either tip up or tip down. Voltage and current leads are attached to the sockets in parallel, passing through the conduit and around the hinge. A short curved rod is attached to the stationary section just behind the hinge, and a spring is attached to this rod and to the movable section. One end of a flexible cord is fastened to the door and the other end to the conduit near the lamp sockets. When the door is opened the sockets are drawn forward to the opening by the cord to facilitate the change of lamps, and upon closing the door they are drawn by the spring to a point about ro inches from the center of the sphere.

The sphere is supported by a low oak platform. Before applying the cement all ribs were fastened to the table by long screws, so that sphere and table are rigidly connected.

\section{SPHERE PAINT}

One of the most important details of an integrating sphere is the use of the proper diffusely reflecting white paint. The use of the zinc white paint recommended by Utzinger ${ }^{33}$ had been contemplated, but it was not possible to find a colorless glue called for in the formula. A number of samples of so-called "flat white" paints were inspected, but none of them proved to be pure white initially, and it is a known characteristic of oil paints that they gradually become yellow with age. Hence it was finally decided 
that the Keene's cement used in surfacing the sphere was the whitest substance available at that time. Two thin brush coats were applied, allowed to dry, and then sandpapered. Even this coating is somewhat selective in absorption, though probably less so than many other coatings in use at present.

The requirements for a satisfactory paint for integrating spheres are unusually severe. To be entirely satisfactory it should fulfill the following conditions:

I. It should be a perfect diffuse:, reflecting light in accordance with the cosine law.

2. It should be tenacious and somewhat elastic.

3. The paint should be a pure white-that is, its reflection should be nonselective-and it must not change in color with age or temperature.

4. The reflection factor should be high.

Of these requirements numbers $I$ and 3 are hardest to fulfill. No oil paint is colorless, and such paints will change in color with age. Although a perfect diffuser is unobtainable, it is possible to make up a paint which will fulfill this condition closely enough for all practical purposes.

When this paint problem arose, extensive experiments were made in the effort to find or develop a suitable paint. It appeared that the most serious defect of all the commercial paints examined was their color. In order to approximately reproduce the distortion of color which results from multiple reflections in the sphere, a test box was made up. It was cubical, with a colorless ground-glass window in one side, and contained a small lamp. The reflecting walls were composed of removable cardboards painted with the paint to be tested. In making a test the walls were first lined with black velvet, and the lamp arranged to illuminate the window directly. This window illuminated the screen of a Lummer-Brodhun photometer. The comparison lamp voltage was then varied until a color match was obtained. Next the black velvet was replaced with the test cards, the direct light was screened from the window, and an effort was made to again obtain a color match.

After a number of samples of commercial "flat white" paints had been tested in this manner, without satisfactory results, an effort was made to develop a suitable paint. D. MacFarlan Moore (discussion ${ }^{35}$ ) had stated that he had found a zinc-oxide paint, using a cellulose lacquer for a binder, to be entirely satisfactory. 
His paint uses amyl acetate, which is expensive and also obnoxious because of the toxic effect of the vapor. In an endeavor to avoid the use of amyl acetate a lacquer was made up by dissolving celluloid and camphor in alcohol. Numerous pigments were tried, the most of the experiments being with magnesium carbonate and oxide, zinc oxide, and barium sulphate. None of these were found to be nonselective, all except the barium sulphate resulting in a greenish-yellow hue which could not be colormatched very closely by a change of voltage of the comparison lamp. It was found that the barium sulphate gave the best results in this respect, and, although it was selective in its absorption, an almost perfect color match was obtainable by reducing the voltage of the comparison lamp. Other difficulties were encountered in trying to make up a paint with this pigment and lacquer and variable results were obtained, so that the effort was finally abandoned.

It was found that a fairly satisfactory paint could be made up with magnesium oxide, but the mixed paint, before being applied, gradually turns yellow, a perceptible change taking place within 24 to 48 hours. There is apparently no change in color after it is applied, however.

Although the zinc oxide paint is somewhat selective in its absorption, it is apparently satisfactory in all other respects, and is now being used in the spheres at the bureau. Before applying it to the concrete sphere the surface was given a priming coat of a thin solution of cabinetmakers' glue. Water glass would probably serve equally well, though this has not been tried.

In preparing the zinc oxide paint, first prepare a lacquer composed of the following:

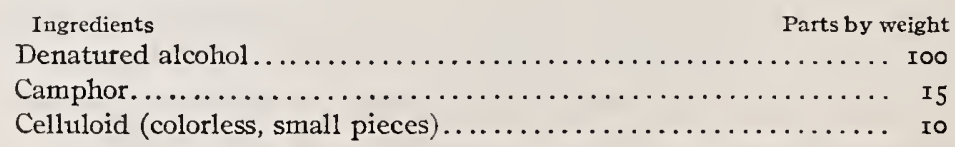

Dissolve the camphor in the alcohol before adding the celluloid, using a motor-operated stirrer. Add the small pieces of clear, colorless celluloid slowly, while stirring, to prevent them from sticking together or to the walls of the vessel. Continue the stirring (covering the vessel) until all the celluloid is dissolved, which usually requires about ro or $\mathrm{r} 2$ hours. This makes a very thick, viscous lacquer. Keep a record of the weights used, so that the alcohol lost by evaporation can be replaced when the celluloid is dissolved. Use care to prevent any zinc oxide from 
getting into the lacquer while dissolving the celluloid, as this has apparently caused trouble at times.

The zinc oxide paint is then prepared by using the following:

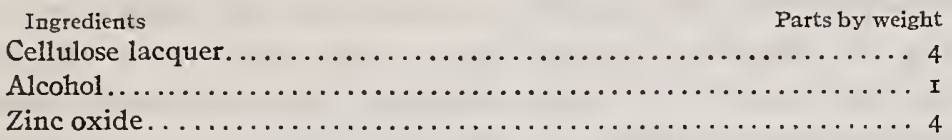

Add the zinc oxide slowly to the lacquer and alcohol, stirring constantly. Continue the stirring until a smooth, thick paste is obtained. This requires about I hour or more. Then add slowly about 2 parts of alcohol and I or 2 parts of water-white turpentine. If not thin enough, add more alcohol. The purpose of the turpentine is to retard drying. It is probable that glycerine could be used instead.

This paint dries very quickly, even on a nonporous surface, and should be brushed out as applied. Care should be taken not to brush over the fresh paint after it has been on Io or I 5 seconds, else the brush will draw the paint. Avoid contact with any water, as water coagulates the paint. Best results will be obtained if drying is retarded by preventing exposure to drafts, etc. In painting a 30-inch metal sphere it has been found best to turn the hemispheres open side up and cover with cloth as soon as the painting is completed. If the paint "checks," add some more camphor. If flaking occurs, make the paint less rich in lacquer. Allow about six or seven hours between successive coats.

This paint is tenacious, is permanent in color, and has a very high reflection factor.

The greenish-yellow hue of the light on the sphere window can usually be almost perfectly matched by the introduction of greenish glass, such as ordinary window glass, on the comparison lamp side. (See sec. I6, "Method of operation.")

\section{PHOTOMETRIC EQUIPMENT}

The photometric equipment consists of a $1.5 \mathrm{~m}$ standard photometer bar, equipped with screens, lamp carriage, sectored disks, recording drum and printing magnet, and a Lummer-Brodhun contrast-type photometer head. The photometer head is arranged so that the window of the sphere is viewed through a lens, to limit the field, and forms one side of the photometric field. The plaster of Paris screen illuminated by the comparison lamp forms the other side of the field. The comparison lamp is shifted by a 
flexible stranded wire belt and pulley arrangement which is operated by a wheel near the photometer head. The position of the comparison lamp for a photometric balance is recorded on a sheet of paper on the recording drum under the lamp carriage by closing an electrical circuit by a push button in the center of the handwheel. This apparatus has been previously described in a publication of this bureau, ${ }^{42}$ but it may be of interest to give a description here. The long cylindrical drum is rotated by an electrical escapement clockwork, adapted to turn the drum o. ${ }^{\circ}$ each time the circuit is closed. The axis of the drum is attached to the axis of the clockwork by a friction clutch, which can be released so that the drum can be rotated at will. A printing electromagnet is rigidly attached to the comparison lamp carriage and moves over the drum lengthwise. This magnet is provided with two revolving spools carrying a typewriter ribbon between the printing point and the sheet on the cylinder. The clockwork and printing magnet are operated in series by a low-voltage battery (Io to 16 volts), the magnet stamping a dot when the circuit is closed, the clock turning the cylinder a small amount when the key opens. The record dots are thus prevented from falling together. In working up observations the average position of each bunch of dots is estimated and marked by a straight line, the position of which is determined by reference to an index line marked on the paper. The drum is turned a small amount between observations on different lamps.

A Brooks type deflection potentiometer is used for the electrical measurements.

\section{COSTS OF CONSTRUCTION}

There have been such large changes in costs of all materials since the construction of this sphere that it seems to be hardly possible to estimate present day costs. The materials used would not be a very large item of cost, but labor would be. It is uncertain whether this type of construction would be less expensive than all-metal construction for the smaller spheres, but for spheres larger than 5 feet in diameter it would very probably be less than for the all-metal sphere.

\section{ADVANTAGES OF BUREAU SPHERE}

Since this sphere differs in many ways from others in present use, it will be of interest to point out its advantages and disadvantages. Most of the large spheres are divisible into halves, one 
of which is on rollers, so that they can be separated for adjustment of arc lamps, etc., in the sphere, and for cleaning and painting. While this sphere is not divisible, it has been found that one can very quickly mount the ladder and make lamp adjustments from above, in fact, probably more quickly than could be done if one hemisphere had to be rolled back. This method of construction also avoids the necessity for a track, which takes up valuable floor space. In order to permit work on the inner surface of the sphere, the bottom section can be lifted out. By means of a stepladder the operator can step into the sphere, and, standing on the floor beneath the bottom opening, he can easily reach any part of the spherical surface.

The sphere is rigid and substantial in construction, has a good surface, continuous (except for necessary openings) and truly spherical, easily repaired or renewed if necessary, and may be ventilated if desired. It is not portable, however.

In operation the sphere has been found to possess distinct advantages due to the use of two sockets for burning lamps either tip up or tip down, and the arrangement for drawing the lamps near to the sphere center, good ventilation when desired, and the use of a standard photometer bar and its accessories.

After having been in use for seven years the surface has shown no signs of cracking or other imperfections.

\section{TESTS OF BUREAU SPHERE}

The principal tests of this sphere have been made to determine the accuracy of integration of sources of different types. For this purpose candlepower distribution measurements of various sources were made on a two-mirror selector, and calculated values of mean spherical candlepower were obtained. Direct measurements of the candlepower of each of the sources were then made in the sphere. The differences between the results obtained by these two methods are shown in the last column of Table $\mathrm{I}$, in which positive values indicate that the results in the sphere were higher than those obtained by distribution measurements, and negative values indicate that the sphere results were lower. The distribution curves for these sources are shown in Figure 3. 


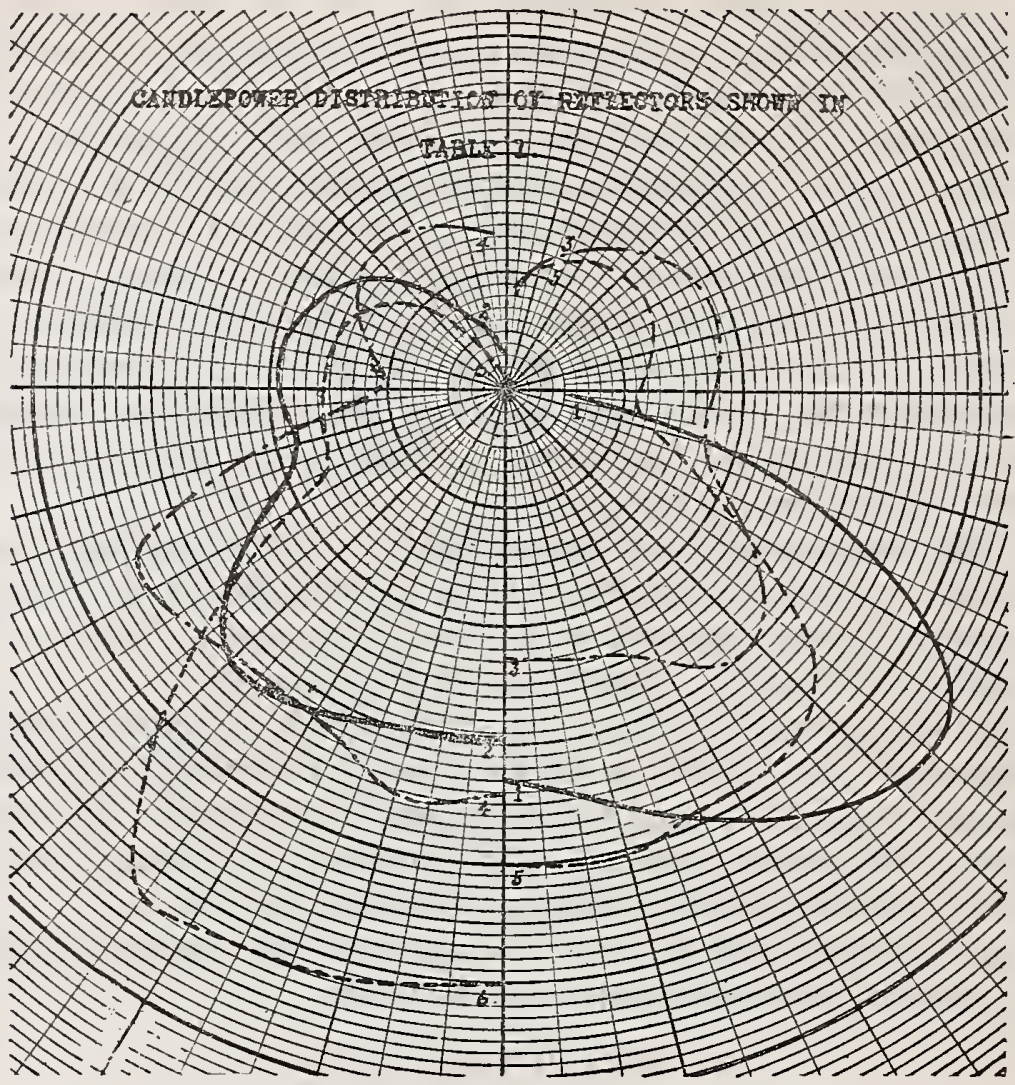

FIG. 3.-Light-distribution curves of reflectors used in tests of sphere

TABLE 1.-Comparison of Integration by Distribution Photometer and Integrating Sphere

\begin{tabular}{|c|c|c|c|}
\hline \multicolumn{3}{|c|}{ Source } & \multirow{2}{*}{$\begin{array}{l}\text { Percent } \\
\text { differ- } \\
\text { ence in } \\
\text { results }\end{array}$} \\
\hline Lamp number $a$ & Accessory & Description & \\
\hline 1 tip up............ & Reflector No. $1 .$. & Porcelain enameled......... & 0.0 \\
\hline 1 tip down........ & ....do.............. & 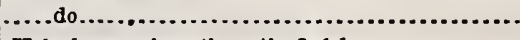 & -.6 \\
\hline $2 \ldots \ldots \ldots \ldots \ldots$ & Reflector No. 2.... & 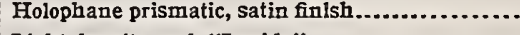 & +.6 \\
\hline $2 \ldots \ldots \ldots \ldots$ & Reflector No. 3... & Light density opal, "Lucida"'...................... & +.8 \\
\hline $2 \ldots \ldots \ldots \ldots \ldots$ & Reflector No. 4... & Light density alba, flaring type.................... & +1.6 \\
\hline $2 \ldots \ldots+\ldots+\ldots$ & Reflector No. 5............. & Heavy density opal "Pheno"....................... & -1.0 \\
\hline $2 . \ldots$ & Reflector No. $6 . . .$. & Holophane prismatic, clear, extensive............... & -.4 \\
\hline $1, \ldots \ldots$ & Globe No. $1 . . . . .$. & 12-inch opal globe, polished, "Polycase" & +.4 \\
\hline $1 . \ldots . \ldots \ldots \ldots$ & Globe No. 2..... & 12-inch opal globe, depolished, “Alabastine”..... & +.5 \\
\hline
\end{tabular}

a I.amp No. r, roo-watt tungsten, clear. Lamp No. 2, 40-watt tungsten, bowl frosted. 
The agreement of the values obtained in the two ways is good, except perhaps for reflector No. 4. The distribution photometer measurements are difficult, on account of the low intensity of the light at many angles (photometer distance was about ro feet) and the error is probably greater in those measurements than in the spherical photometer. No value shown in the table is the result of many measurements, hence the differences are very probably due partly to experimental errors.

\section{ABSORPTION OF REFLECTED LIGHT BY FOREIGN OBJECTS}

In order to measure the absorption of diffusely reflected light by black objects of various shapes and sizes, a number of these were made up and painted with lampblack in shellac. Lamp No. I was burned tip down in reflector No. I, and the test object was suspended near the center of the sphere, where no direct light could fall on it. The test object was also screened from the sphere window. The results are shown in Table 2. Where the test object is designated as "double disk," a disk blackened on both sides was used, and where the term "single disk" is used, a circular disk blackened on one side, and fastened to the sphere screen, on the side away from the window, is indicated. The absorption values shown in the table indicate the amount by which the sphere window illumination was reduced when the objects were suspended in the sphere. The reduction to be expected is shown by equation (I8), to be $\frac{S a^{\prime}(\mathrm{I}-a)}{a A}$. Hence, if this equation is correct, the values in the last column of the table should all be equal, since $S$ is presumably the only variable in the equation. The differences found, with the exception of the last two, are probably errors of measurement, since the calculation is a severe test of the accuracy of the measurements. For example, if the observed absorption by the cylinder were 0.5 per cent higher, the value in the last column would be i I.4 instead of ro.7. The lower values for the two globes were probably due to their having cut off some light from the opaque screen used to screen the window, thereby reducing the total amount of flux received and absorbed by them. Apparently the absorption is independent of the shape of the objects, as was to be expected.

$100904^{\circ}-22-3$ 
TABLE 2.-Absorption of Reflected Light by Black Objects of Various Shapes and Sizes

\begin{tabular}{|c|c|c|c|c|}
\hline Object & Area & $\begin{array}{c}\text { Sphere } \\
\text { area }\end{array}$ & $\begin{array}{c}\text { Absorp- } \\
\text { tion }\end{array}$ & $\begin{array}{l}\text { Ratio of } \\
\text { percent- } \\
\text { age } \\
\text { absorp- } \\
\text { tion to } \\
\text { percent- } \\
\text { age of } \\
\text { sphere } \\
\text { area }\end{array}$ \\
\hline & $\mathrm{Cm}^{2}$ & Per cent & Per cent & \\
\hline $\begin{array}{l}\text { Single dlsk } \ldots \ldots \ldots \ldots \ldots \ldots \ldots \ldots \ldots \ldots \ldots \ldots \ldots \ldots \ldots \ldots \\
\text { Double disk }\end{array}$ & $\begin{array}{l}1152 \\
1078\end{array}$ & 0.738 & $\begin{array}{l}7.89 \\
7.65 \\
\end{array}$ & $\begin{array}{l}10.7 \\
11.1\end{array}$ \\
\hline Cube & 1110 & .711 & 8.20 & 11.5 \\
\hline 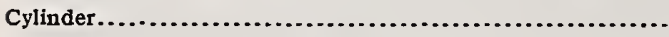 & 1122 & .719 & 7.69 & 10.7 \\
\hline Globe No. 1................ & 2012 & 1.288 & 12.9 & 10.0 \\
\hline Globe No. $2 \ldots .$. & 3007 & 1.925 & 18.4 & 9.6 \\
\hline
\end{tabular}

Tests to determine the amount of absorbtion of reflected light by clear lamps of sizes from 50 -watt carbon to 250 -watt vacuum tungsten indicated that the absorption was negligible, being less than the uncertainty of measurement except in the case of large lamps with skirted bases.

\section{REFLECTION FACTOR OF SPHERE COATING}

The reflection factor of the sphere coating was determined in two ways, one determination being carried out on a separate sample of the material and one on the complete sphere. For the latter test the milk-glass window was removed from the sphere wall, placed on the photometer bar, and a portable photometer pointed at it. A standard lamp was arranged at a measured distance from the milk glass, and the photometer standardized to measure the illumination on the glass. The window was then replaced, and the illumination on the window measured when the same standard lamp was burned in place in the sphere.

Three measurements of illumination were made, namely, with window screened, window unscreened but screen remaining in the sphere, and screen removed from sphere. The difference between the first two measurements was the amount of direct illumination thrown on the window by the lamp alone, and this was subtracted from the illumination value obtained when the screen was removed from the sphere. The calculation of the absorption by the sphere walls is then as follows (for the development of this theory see Part II): 
Let

$E=$ average total illumination on sphere wall;

$E_{d}=$ average direct illumination $=\frac{\mathrm{m} \text {. } \mathrm{s} . \mathrm{cp}}{(\text { radius })^{2}} ;$

$E_{m}=$ illumination by reflected light;

$=$ measured illumination $=E-E_{d}$;

$m=$ reflection factor;

$a=$ absorption factor.

$E=\frac{E_{d}}{I-m}=\frac{E_{d}}{a}=E_{d}+E_{m}$;

$a=\frac{E_{d}}{E_{d}+E_{m}}$.

Calculations of the observed data on the Keene's cement surface, using this formula, gave an absorption value of 8.I per cent, or reflection factor of 9 r.9 per cent.

These measurements indicated a very high reflection factor, much higher than had been believed to be possible, as a previous investigator had given 88 per cent as the reflection factor of magnesium carbonate. ${ }^{41}$ Repetition of the measurements checked this result, and consequently steps were taken to verify it by another method. In this method the surface brightness of a flat disk of the cement was measured at every $10^{\circ}$ when illuminated normally to a known value. These measurements gave further confirmation of this result. Later another coat of the Keene's cement was applied and the absorption factor was then found to be 7.5 per cent, a distinct improvement over the previous coating.

A measurement of the absorption by the method suggested by Chaney (discussion ${ }^{35}$ ), namely, directing a narrow beam of light first at the screened area opposite the test plate, and, second, entirely within the unscreened area, gave a result in very close agreement with the above value.

This sphere has recently been painted with the zinc-oxide paint described above, and the absorption factor remeasured. It was found to be 6.0 per cent when the surface was fresh. This value was further verified by measurement by another method.

As an outgrowth of this work one of the authors has given special attention to the improvement of methods for the measurement of reflection factors, and has devised two types of reflectometers ${ }^{40,44}$ in which the principles of the integrating sphere are applied. Results with these new instruments have corroborated the high values of reflection factor mentioned above. 


\section{EFFECT OF LAMP POSITION}

The change of sphere window illumination when a clear lamp without reflector was placed in various positions was measured, and the results are shown in Figure 4. The lamp used was a vacuum tungsten lamp. Two methods of varying the position were used, namely, first, by setting the lamp-socket arm at various distances from the door, and, second, by suspending the lamp from a cord at various distances from the door, in each case the direct light being screened from the observation window by an opaque screen $38 \mathrm{~cm}$ in diameter. The results were practically the same when a small lamp was tested by the suspension method. This apparently indicated that the change in window illumina-

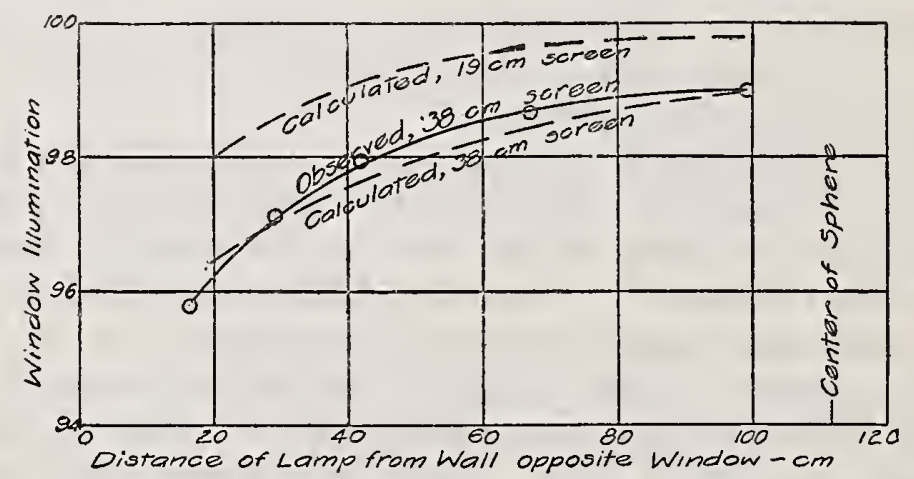

Fig. 4.-Effect of position of lamp on illumination of sphere window

Data for multiple vacuum tungsten lamp. The ordinates are percentages of the illumination which the same lamp would produce in the empty sphere by reflected light only

tion was not due to absorption of light by the lamp. When the small lamp was moved toward either of the side walls $90^{\circ}$ from the window, being so arranged that no direct light reached the observation window, but without employing any large opaque screen, the window illumination did not decrease as the lamp approached the wall, but, on the contrary, increased slightly. These and other tests definitely show that the observed decrease of window illumination as the lamp approached the screened wall was due to the fact that more and more of the direct light fell on the screened areas and had to be reflected at least twice before reaching the window.

From the known values of the light distribution of a lamp of this type and the absorption of the sphere wall it is possible to calculate the decrease to be expected. Such values have been calculated for two sizes of screen, of 38 and $19 \mathrm{~cm}$ dianeter, respec- 
tively, and plotied as solid curves in Figure 4. For the $38 \mathrm{~cm}$ screen the observed curve has arbitrarily been given the same value as the calculated curve for the position nearest the center of the sphere. The close agreement between calculated and observed curves confirms the reason advanced above for the observed change. In neither case is the reduction of total illumination due to absorption of multiple reflected light by the opaque screen taken into account, but it is not necessary to do so, since it is practically independent of the light distribution or position of the lamp. The method by which the calculated curve was obtained will be explained in the second part of this paper.

If a light source of extended area, such as a diffusing globe, is brought near the screened sphere wall, a decrease greater than that shown by Figure 4 will be observed, for in addition to the greater flux on the screened area there will be the additional effect of greater absorption by the globe itself, since it receives a greater fraction of the first reflected flux than when it is nearer the center of the sphere.

Probably the greatest error which occurs in the use of integrating spheres is caused by placing the lamps too near the sphere wall and making no correction for light absorbed by them. When testing life-test lamps in this manner, where the lamp may be appreciably blackened and consequently absorbs more reflected light than it did when new, the error is undoubtedly too large to be neglected.

\section{SELECTIVE ABSORPTION BY THE SPHERE SURFACE}

In the bureau sphere, as is probably the case everywhere, there is some selective absorption by the sphere wall coating. Since this is such a general condition, it is desirable to know whether or not it causes any error, and if so, approximately how much. A test to determine the amount of selectivity, or, in other words, the difference between the color of the light given out by a lamp and the color of the light emerging at the window, was made when the surface was coated with Keene's cement. For this purpose the sphere window was removed and placed on one side of the photometer. When a vacuum lamp of an efficiency of about I.2 watts per horizontal candle illuminated the window directiy, the comparison lamp gave the nearest color match at 98 volts, with an efficiency of $\mathrm{I} .33$ watts per horizontal candle. (This difference is due to selective absorption by the milk-glass window.) The first lamp was then placed in the sphere, burned 
at the same voltage, and the voltage of the comparison lamp altered until the best color match was again obtained. Its voltage was then 70 , and its efficiency approximately 2.75 watts per horizontal candle. A perfect color match is not obtainable in either case, partly because of selective absorption by the milk-glass window. Although this characteristic of milk glass probably does not cause any appreciable error of measurement, it does make the photometric observations somewhat more difficult.

In order to determine whether or not any error of measurement results from selective absorption by the sphere walls, the amount of which has already been described, the following experiment was performed:

Two lamps of the same type were selected. One of these was used as the comparison lamp, and the other was put in the sphere. The voltages were set to give about the same efficiency, that is, about I.I wphc, and a reading taken. The voltages of both lamps were then altered until an efficiency of about 3.15 wphc was obtained, and another reading taken. Since there is a large color difference encountered in reading the photometer when the lamp is in the sphere, evidently about equal for both conditions, precautions were taken to keep outside of the range of the Purkinje effect by making the illumination of the photometer screen practically equal in both cases.

The lamp was then removed from the sphere and arranged to illuminate the milk-glass window, which had been set up on the bar photometer. The measurements at the two efficiencies were then repeated.

If there is no error due to the selective absorption, the ratio of the illumination of the sphere window at the two voltages with one lamp in the sphere should be the same as that obtained when the lamp was measured on the bar photometer. If there is any error, it would be expected that the lamp in the sphere would be underrated at the higher efficiency on account of the greater absorption of the whiter light.

The ratios of the illumination in the two cases differed by only 0.4 per cent, which was within the error of measurement, since the measurements in the sphere were difficult because of the color difference. It is to be noted, also, that the difference was in the direction opposite to that to be expected if there was any error introduced by the selectivity. Hence it seems safe to conclude that over this range of color difference no measurable error 
due to selective absorption applied to measurements made in this particular sphere.

At present it is very difficult to obtain for the window a diffusing material which does not have some selective absorption. Milk glass usually has a higher absorption in the blue end of the spectrum, while clear glass in great thicknesses is usually green.

Experimental work at the bureau has shown that good milk glass loses practically nothing in diffusion properties by being ground down to a thickness of less than I $\mathrm{mm}$, while a very appreciable gain will be made in reduced selective absorption and increased transmission. The surface toward the sphere should be given the coarsest possible grinding with coarse carborundum or by sandblasting.

\section{METHOD OF OPERATION}

The "substitution" method which is used in practically all the photometric work in the bureau makes possible the adjustment of the apparatus to the best condition of measurement in every case. This method also obviates any necessity for long-continued constancy of many factors in the measurements, such as the candlepower of the comparison lamp, the reflection factor of the shpere walls, etc.

The illumination on either side of the photometer screen is varied in part by the use of a set of sectored disks, depending on the well-known law that if the illumination of any surface is obstructed by means of a rapidly rotating sectored disk, the apparent brightness of the surface is directly proportional to the angular opening of the disk. In certain cases neutral absorption glass screens are used, though usually this is done only where the factor for the glass need not be known.

When the color of the light from the test lamps is very different from that from the standard lamps, it is desirable to use some method of altering the color of incident light from the comparison lamp in order to facilitate the measurements and free them from this element of uncertainty. The method used here is the interposition in the path of the light of glass cells filled with colored liquids. These are made up by trial, and in cases where it is necessary to know the relative transmissions, this standardization is made by means of a flicker photometer. The solutions used are water solutions of potassium bichromate and of copper sulphate. The desired color can be approximated by varying the densities of the solutions or by mixing them. In the use of such cells, if the 
relative transmissions must be known, the measurements should be made with a lamp of the same color as the comparison lamp to be used. Also, it is undesirable to use the cells to alter the light from the sphere, for this light varies in color according to the color of the lamps tested, and the transmission of a solution is known to be appreciably different for lights widely different in color.

Another method which has proved very successful is the use of ordinary window glass which has a greenish hue. When used of the proper thickness, on the comparison lamp side, it is usually possible to obtain a nearly perfect color match with the paint described above, and in some other cases. When used in this manner a correction should be made for the change in length of the optical path. Insertion of the glass has the effect of shortening the optical path, so that it is less than the measured distance by an amount approximately equal to one-third of the thickness of the glass.

To facilitate the work of evaluating the readings an inverse square scale, with divisions expressing percentages, was ruled on a transparent triangle. By setting an index line on the triangle to coincide with an index line on the sheet on which the photometer readings have been printed by the electromagnet, the proportionalities of the various readings can be read off. By the aid of a slide rule these are easily convertible into candlepower values.

In the case where lamps not widely different in candlepower are to be measured, a candlepower scale can be prepared. The variation of the intensity of the comparison lamp throughout a small voltage range where it is to be used should be experimentally determined, so that small adjustments can be made by varying its intensity. The method of measurement most easily carried out would then be somewhat as follows:

Put a standard lamp in the sphere, and set the comparison lamp at the point on the scale to make it read directly the spherical candlepower of the standard lamp, first having determined the voltage of the comparison lamp for a color match with the standard. Next alter the position of the secondary sphere window (if a double window such as that described above is used) until an intensity match is obtained. Take readings on several standard lamps, and if it is found that they read high or low by a small amount, change the voltage of the comparison lamp by the predetermined small amount necessary to make the read. 
ings correct. Readings on one or more standard lamps should be made at frequent intervals throughout the run, to check the accuracy of the measurements. Where high precision is desired, a number of standard lamps should be read both at the beginning and the end of the observations, and if the results in the two cases do not agree, an adjustment of the values must be made or the run discarded if the disagreement exceeds a permissible amount.

The above method applies to the use of a sphere with which a bar photometer is used. With such a photometer bar a regular Lummer-Brodhun sight box can be used, one side of the sight box being removed so that the sphere window forms one side of the photometric field.

It is possible also to use a portable photometer, such as the Sharp-Millar, which has an inverse square scale, but it is evident that the use of such an instrument will not give an accuracy as high as that obtainable with a bar photometer and accessories.

In measurements of light sources having surfaces which absorb an appreciable amount of light, the following procedure, which is the general practice, is probably best:

The opaque screens to be used are placed in position, and a reading of the standard lamp, without the test lamp in the sphere, is taken. Next, a small shield is arranged to screen from the test lamp when in position any direct light from the standard lamp, and another reading is taken. The test lamp is then brought into the sphere, in the position which it is to occupy, but unlighted, and another reading is taken. The percentage difference between the readings in the last two cases is the reduction of sphere window illumination due to the absorption of reflected light by the test lamp. When the readings of the test lamp are evaluated in terms of the reading of the standard lamp in the empty sphere this percentage should be added to the results. This is a very important correction, as appreciable errors may occur if it is not taken into accounc. A modified procedure consists in taking readings on the standard lamp when the test lamp is in the sphere, and evaluating the results on the test lamp directly in terms of the readings on the standard lamp. In this method, as before, precautions should be taken to screen from the test lamp the direct light from the standard lamp. The former method has an advantage if many lamps of the same kind are to be measured, or if the same lamp is to be measured many times, since in that case a constant percentage correction can be applied to the obser- 
vations evaluated in terms of observations on standard lamps in the empty sphere.

It is good practice to cover large absorbing surfaces, such as arc lamp mechanism casings, with white paper or cardboard, whenever it can be done in such a manner as not to cut off any light emitted by the lamp.

\section{SPECLAL USES OF INTEGRATING SPHERES}

In addition to the measurement of mean spherical candlepowers the sphere may be used to make other important measurements. Its use for hemispherical candlepower measurements has been extensively discussed in some of the articles listed in the bibliography. It can also be used for the measurement of the effective light flux within a given solid angle. (See discussion of reference, ${ }^{35}$ by Chillas.) For these measurements a sphere divisible into hemispheres is more useful. The use of the hemispheres for measurements on searchlight beams has been described by Benford. ${ }^{38}{ }^{39}$

The integrating sphere principle has recently been applied to the measurement of diffuse reflection factors by one of the present authors. ${ }^{40}$ Its use for this purpose promises to fill a long felt want.

The testing of jewels for the Panama-Pacific International Exposition is an interesting application of the sphere which has been described by S. L. E. Rose (discussion ${ }^{31}$ ). Many other applications of the apparatus will doubtless be made in future.

\section{CONCLUSION}

It may be said in conclusion that the authors believe that in the hands of careful and experienced photometricians a properly designed sphere will give very accurate results, and forms one of the most important parts of the equipment of a photometric laboratory.

Since the present types of lamps vary greatly in their light distribution, and change differently in distribution as they are burned (as, for example, in a life test), the only true basis of comparison is in terms of their spherical intensity or total flux, and this is rapidly becoming the accepted practice.

The sphere described above has proved very satisfactory in practice, and is in more nearly constant use than any other apparatus in the photometric laboratory.

The authors are.indebted to E. C. Crittenden for many helpful suggestions and for the selection of the photometric equipment. 


\section{PART II.-THEORY}

[By A. H. Taylor]

\section{INTRODUCTION}

The theory of the Ulbricht sphere has been extensively treated in the literature listed in the accompanying bibliography, but a great deal of the discussion is a repetition of certain phases of the general theory, and in no one place is there a complete discussion of all details of the theory. Hence it has been thought desirable to give here a fairly complete résumé of the theory, together with new developments of certain phases, with especial regard to the best design of the sphere to increase the accuracy of measurement.

In preparing this paper the works of Ulbricht, ${ }^{815}$ and Chaney and Clark ${ }^{31}$ have been freely consulted, as they have given the most complete discussions of the theory available until very recently, but a large part of the applied theory given here is new. In a number of other parts new methods of development which are believed to be less complex than those previously used have been followed.

\section{GENERAL THEORY}

Theoretical photometry makes use of two general laws of radiation; first, that the intensity of illumination of a surface is inversely proportional to the square of its distance from the light source, and, second, the cosine law of emission, of ten erroneously referred to as Lambert's cosine law, ${ }^{43}$ which states in substance that the luminous intensity of an element of a perfectly diffusing luminous surface is directly proportional to the cosine of the angle between the normal to the surface and the line of emission. From the latter law it follows that the brightness of such a surface is independent of the angle of view and that the luminous intensity is directly proportional to the projected area. No luminous surface obeys this law exactly, but it is possible to produce a surface which will approach fulfillment of the law. For simplicity in the following theoretical treatment exact fulfillment of the law is assumed, unless otherwise stated. The effect of deviations from exact fulfillment is discussed later in this paper.

In considering the general theory of the sphere certain relations between brightness and the luminous flux emitted or received will be found very useful. The proofs can be found in another Scientific Paper of this bureau, ${ }^{27}$ or they can be derived very simply 
by the methods of the integral calculus. These relations are as follows:

Unit area of a plane disk radiating luminous flux in accordance with the cosine law of emission-that is, one which has the same brightness $b$ (candles per unit of projected area) at all angles of view-radiates a total flux of $\pi b$ lumens.:

A unit plane illuminated by a parallel infinite plane of uniform brightness $b$ receives $\pi b$ lumens.

Given a hollow sphere (Fig. 5) with a surface radiating light flux in accordance with the cosine law of emission, let

$r=$ radius of sphere;

$d S=$ area of small surface at $P$;

$b=$ brightness (candles per unit area) of $d S$;

$E_{1}=$ illumination (foot-candles) at $P_{1}$ due to $d S$.

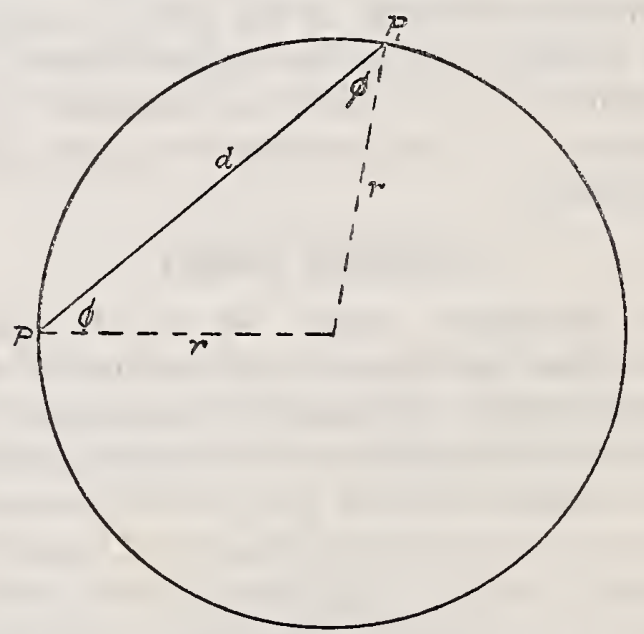

FIG. 5.-Relation between emitting and illuminated elements of sphere

The candlepower of $d S$ in the direction $P P_{1}$ is $b d S \cos \phi$, and the illumination it would produce on a plane at $P_{1}$ normal to $P P_{1}$ would be $\frac{b d S \cos \phi}{d^{2}}$. Since the surface at $P_{1}$ is at an angle $\phi$ to the line $P P_{1}$, the illumination at $P_{1}$ due to $d S$ alone will be

$$
\mathrm{E}_{1}=\frac{b d S \cos \phi}{d^{2}} \cos \phi
$$

But $d=2 r \cos \phi$, and therefore

$$
E_{1}=\frac{b d S \cos ^{2} \phi}{4 r^{2} \cos ^{2} \phi}=\frac{b d S}{4 r^{2}} \text {. }
$$

*The lumen is the unit of luminous flix, equal to the flum emitted is a unit solid angle (steradian) by a point souree of unit candlepower. 
Since $P_{1}$ may be any point on the interior surface of the sphere, it is evident that any element of surface illuminates all other elements of the surface equally. Hence, in a sphere having a surface which reflects light in accordance with the cosine law, the illumination of the surface by reflected light only is equal at all points, regardless of any asymmetry of the light received directly from the source or of any variation of the reflection factor of the surface from point to point.

$E_{\mathrm{d}}=$ the average illumination (foot-candles) of the sphere surface by light received directly from the lamp;

$E_{\mathrm{m}}=$ the illumination by diffusely reflected light only;

$E=$ the average total illumination;

$m$ = reflection factor of the sphere surface;

$a=$ absorption factor of the sphere surface.

$=\mathrm{I}-\mathrm{m}$;

$F=$ total light flux (lumens) radiated by lamp in sphere;

$A$ = area of sphere surface.

$E_{\mathrm{m}}$ is composed of light of which a portion has been reflected a great many times, and hence $E_{\mathrm{m}}=m E_{\mathrm{d}}+m^{2} E d+\ldots \ldots$ etc.

$$
\begin{aligned}
& E=E_{\mathrm{d}}+E_{\mathrm{m}}, \text { or } \\
& \quad E=E_{\mathrm{d}}\left(\mathrm{I}+m+m^{2}+\ldots \ldots+m^{(\mathrm{n}-1)}\right)=E_{\mathrm{d}} \frac{\mathrm{I}-m^{\mathrm{n}}}{\mathrm{I}-m} .
\end{aligned}
$$

Since $n$ is infinite,

$$
E=\frac{E_{\mathrm{d}}}{\mathrm{I}-m}=\frac{E_{\mathrm{d}}}{a}
$$

This result can be obtained by other methods also, one of which is as follows:

Since the hollow sphere is a closed surface, all of the light flux radiated by the lamp will be absorbed. The intensity of the total illumination will depend on the absorption factor of the surface. An analogy to this is the strength of the current in a resonant electrical circuit.

Hence

$$
a E A=F^{*}, E=\frac{F}{a A}=\frac{E_{\mathrm{d}}}{a} \text {, since } \frac{F}{A}=E_{\mathrm{d}} .
$$

\section{ERRORS OF MEASUREMENT DUE TO SCREEN}

The illumination of any particular point may differ from $E$, since the direct illumination $E_{\mathrm{d}}$ varies with the light distribution of the source and its distance from the point considered. In order to measure $E_{\mathrm{m}}$, which is directly proportional to $I$, the spherical

ik Since an illumination of one foot-candle is produced by one lumen incident per square foot. 
candlepower of the lamp, it is necessary to insert in the sphere wall a diffusely transmitting window and to screen from it the direct light from the lamp in the sphere. Relative values of the brightness of the window are then proportional to the relative spherical intensities of the lamps tested. However, the necessary use of the screen to cut off the direct light from the window, and the insertion of the lamp into the sphere alter the above theoretical value of $E_{\mathrm{m}}$ somewhat on account of obstruction and absorption of light by them, and it is important to know the magnitude of the possible error which may occur.

In a sphere in which the direct light is screened from the observation window the direct light may be considered as having two components as regards its effect on the brightness of the observation window, namely, the part $A$, which is incident on the surfaces visible from the observation window, and the part $B$, which falls on the areas screened from the window. The part $A$ can illuminate the window by the first reflection, but the part $B$ must suffer one extra reflection before any of it can reach the window. Any constant difference between the theoretical and observed values of $E_{\mathrm{m}}$ will be compensated for by the substitution method of photometry, but variable differences, due to different fractions of the total direct flux of the two lamps being incident on the screen and screened area, will cause errors of measurement.

Let $\delta=$ fraction of total light flux $F$ incident on screen and screened area.

The portion of direct light reflected from the zone unscreened from the observation window (zone 3, Fig. 6) is $m F(I-\delta)$. Its effect on the observation window is the equivalent of a secondary source radiating that amount of light flux in an empty sphere. Hence the illumination of the observation window due to it is $\frac{m F(\mathrm{I}-\delta)}{a A}$. The portion $\delta F$ suffers two reflections before any of it reaches the observation window, and its effect on the window is the equivalent of a source radiating $m^{2} \delta F$ lumens. Hence the total illumination of the window is

$$
\begin{aligned}
E^{\prime} & =K\left[\frac{m F(\mathrm{I}-\delta)}{a A}+\frac{m^{2} \delta F}{a A}\right] \\
& =\frac{m F K}{a A}[(\mathrm{I}-\delta+m \delta)]=K^{\prime}(\mathrm{I}-\delta a),
\end{aligned}
$$

where $K$ is a proper fraction introduced to make allowance for the absorption of reflected light by the lamp and opaque screen. 
The factor $K$ is practically constant if the screen is small, but $\delta$ is variable, being dependent on the distribution of light from the source. Its value may be anything between $o$ and $I$, being o if no direct light is incident on these areas. Hence the maximum possible error is $a$, the absorption factor of the sphere surface.

If the substitution method of photometry is used, the error of measurement $e$ would be given by the equation

where

$$
e=\frac{\left(\delta^{\prime}-\delta^{\prime \prime}\right) a}{\mathrm{I}-\delta^{\prime} a},
$$

$\delta^{\prime}=$ value of $\delta$ for standard lamp;

$\delta^{\prime \prime}=$ value of $\delta$ for test lamp.

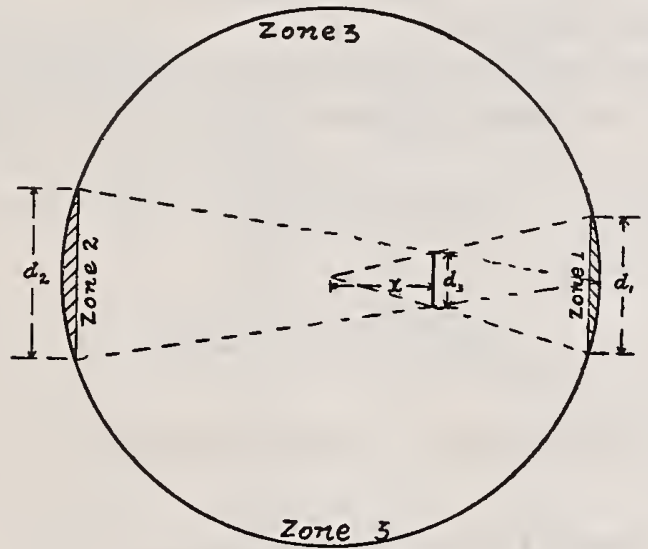

FIG. 6.-Screened and unscreened zones of sphere with light source at center

Zone $I$ is screened from the source, and the observing window is placed in it. Zone 2 is therefore screened from the window. Zone 3 is not screened from either source or window.

\section{POSITION AND SIZE OF SCREEN}

As has been indicated above, errors are caused by the screen only when different fractions of the direct flux of the two sources being compared fall on the screen and screened area. Assuming that the screen has the same reflection factor as the sphere surface, its effect on the light which falls directly upon it is practically the same as if an equivalent zone (zone I, Fig. 6) were screened from the observation window. In general, it is evident that the smaller this equivalent zone and the zone actually screened from the window (zone 2, Fig. 6) are made, the less chance there will be of errors resulting. 
The proper position of the screen to make the screened areas a minimum can be determined closely enough by drawing a diagram of the sphere, with different positions of a-screen of constant size. and finding the point at which the sum of the squares of the diameters of the screened areas on the sphere walls will be a minimum. The position can be more exactly determined mathematically as follows:

Lamp at center of sphere. (See Fig. 6.)

Let $d_{1}=$ diameter of zone $\mathrm{I}$;

$d_{2}=$ diameter of zone 2 ;

$d_{3}=$ diameter of screen;

$x=$ distance of screen from center of sphere;

$y=$ sum of areas of zones I and 2;

$r=$ radius of sphere.

Zones I and 2 are the screened zones. It is desired to make $y$ a minimum. An approximate solution would be obtained as follows:

$$
\begin{aligned}
& \frac{d_{1}}{d_{3}}=\frac{r}{x}, d_{1}=\frac{d_{3} r}{x} . \\
& \frac{d_{2}}{d_{3}}=\frac{2 r}{r-x}, d_{2}=\frac{2 d_{3} r}{r-x} .
\end{aligned}
$$

Area of zone I (approximately) $=\frac{\pi d_{1}^{2}}{4}$.

Area of zone 2 (approximately) $=\frac{\pi d_{2}^{2}}{4}$.

$$
\therefore y=\frac{\pi}{4}\left(d_{1}{ }^{2}+d_{2}{ }^{2}\right)=\frac{\pi d_{3}^{2}}{4}\left[\left(\frac{r}{x}\right)^{2}+\left(\frac{2 r}{r-x}\right)^{2}\right] \text {. }
$$

Differentiating and equating to $o$ gives the condition for a minimum of screened area.

$$
\frac{d y}{d x}=\frac{\pi r^{2} d_{3}^{2}}{2}\left[\frac{4}{(r-x)^{3}}-\frac{1}{x^{3}}\right]=0, \frac{4}{(r-x)^{3}}-\frac{\mathrm{I}}{x^{3}}=0, \text { or } 4 x^{3}=(r-x)^{3} .
$$

Then $x=0.387 \mathrm{r}$.

The value of $x$ when the lamp is not in the center of the sphere could be calculated in a similar manner, though the calculation would be more complex because the screened zones would not be circular. In that case the solution is most easily obtained by graphical methods. 
If the lamp is above or below the center of the sphere, so that the line from the lamp to the observation window makes an angle $\theta$ with the line from the window to the center of the sphere, the window being on a horizontal diameter of the sphere, the proper horizontal distance of the screen from the vertical axis of the sphere is given by Ulbricht as follows:

$$
\begin{aligned}
& \theta=30^{\circ}, x=0.32 r ; \\
& \theta=35^{\circ}, x=0.29 r .
\end{aligned}
$$

By the graphical method suggested above the proper positions for the screen for varying positions of the lamp on a diameter

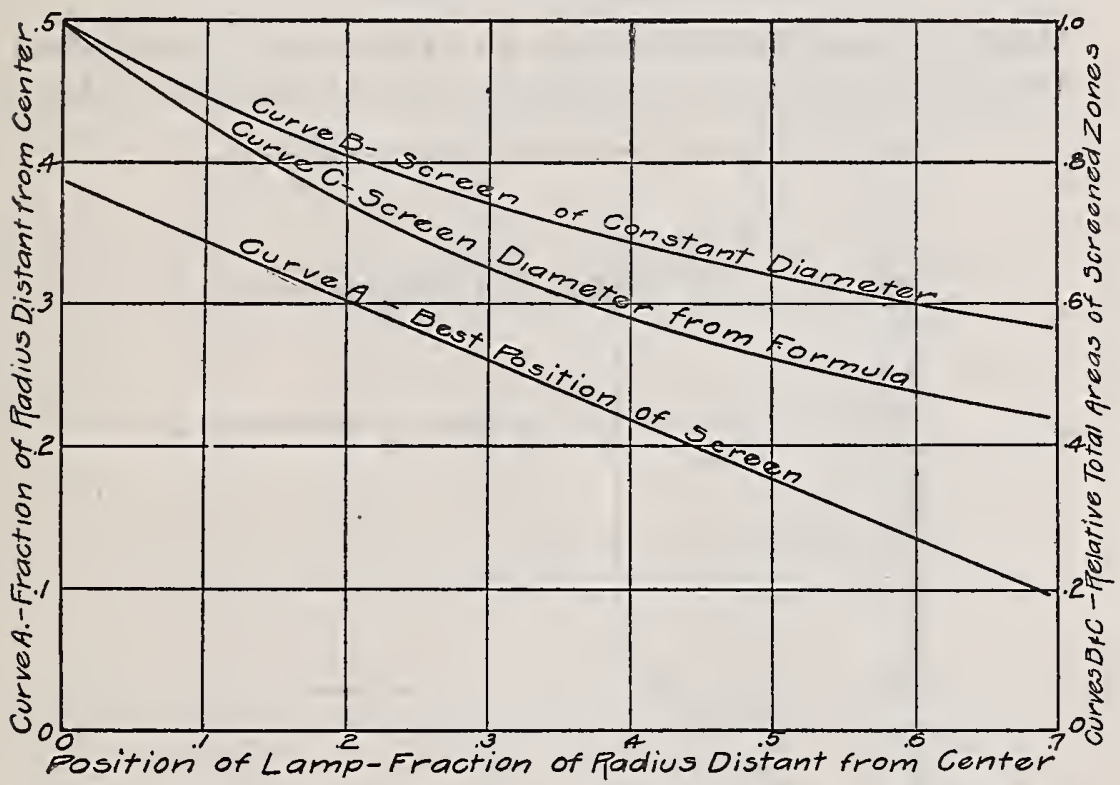

FIG. 7.-Best position of screen, and relative areas screened by it with lamp in different positions

through the window have been determined. The result is shown by curve $A$ of Figure 7. The lamp and screen are assumed to be on opposite sides of the center of the sphere, with the screen on the side toward the window. The solution was obtained for a screen whose diameter was o.r that of the sphere, but a check calculation with a screen double that diameter gave substantially the same result. The sum of the screened areas decreases as the lamp is moved farther from the sphere center, the screen being placed in the position shown by curve $A$. This result is shown by curve $B$. The necessary diameter of the screen to give good screening also decreases. The diameter of the screen required 
when the screen and lamp are on opposite sides of the sphere center may be determined as follows:

Let $l=$ the greatest dimension of lamp to be screened, or length of locus of light source;

$r=$ radius of sphere;

$a r=$ distance of lamp from center of sphere;

$b r=$ distance of screen from center of sphere;

$d=$ required diameter of screen. Then

$$
\frac{d}{l}=\frac{(\mathrm{I}-b) r}{(\mathrm{I}+a) r}, \text { or } d=l \frac{\mathrm{I}-b}{\mathrm{I}+a} .
$$

Hence it is seen that the diameter of the screen is independent of the size of the sphere, and depends only on the positions of lamp

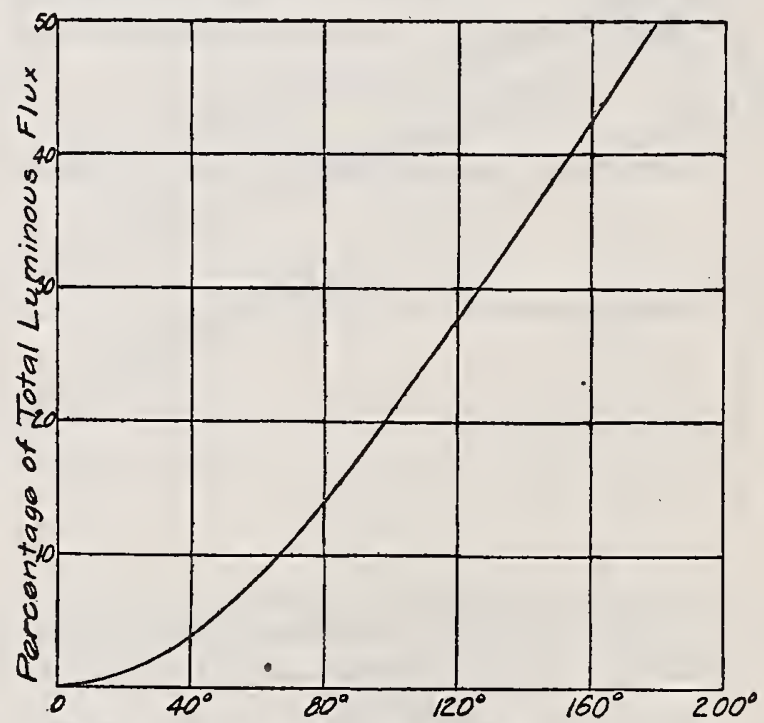

Angle of Cone whase Axis is Normal to Axis of Filaments

FIG. 8.-Percentage of total flux from vacuum tungsten lamp included in cones of various apertures normal to lamp axis

and screen and the length of the largest lamp which it is desired to measure (assuming that one screen is to serve for all lamps. If the lamps vary much in size, it may be desirable to have a series of interchangeable screens). For safety the screen should be made slightly larger than the solution given by (13). Curve $\mathrm{C}$ in Figure 7 shows the relative total areas of the screened zones for various positions of lamp and screen, when the screen diameter is chosen by equation (I3) and the screen is located according to curve A, Figure 7 . 
In Figure 8 is shown, for the common type of vacuum tungsten lamp, the percentage of the total light which is emitted in cones of various angles with their axes normal to the axis of the filaments. The angle of the beam incident on each screened area is easily obtained, and by reference to this curve the percentage of the total flux which is incident on the screened area may be found. If when the lamp is in the center of the sphere the diameter of the proper screen is 0.2 or 0.4 of the sphere radius, its proper diameter for other positions of the lamp is shown by the solid curves of Figure 9, and the percentage of the total flux of a vacuum tungsten

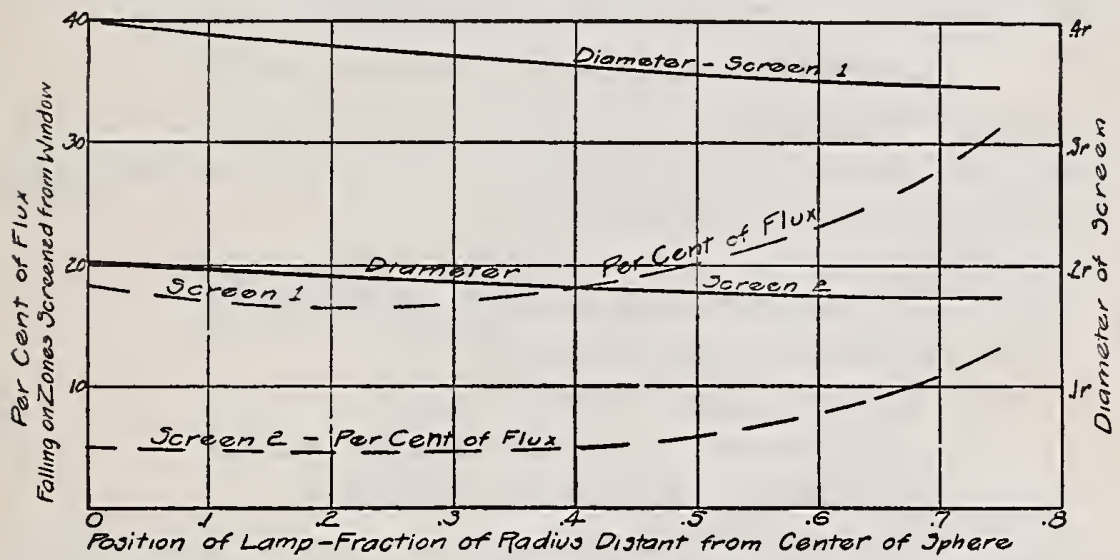

FIG. 9.-Diameter of screens and percentage of light flux falling on parts screened from observing window with lamp in different positions

It is assumed that the lamp is such as to require a screen diameter either ( 1 ) 0.4 or (2) 0.2 of the sphere radius when the lamp is at the center of the sphere. Diameters for other positions are then calculated from equation $\mathrm{I}_{3}$, and positions are determined by curve $A$, Fig. 7. The flux calculations apply to vacuum tungsten lamps (see Fig. 8). The percentage of flux indicated falls on the screen and on the zone screened from the window, but both of these may be considered as zones of the sphere wall (see Fig. 6)

lamp which is incident on the zones screened from the window is shown by the broken curves in the same figure.

This type of lamp gives more nearly than any other common type of incandescent lamp the light distribution which would be obtained from a straight luminous rod, and it is improbable that any other type of filament arrangement except the motion picture projection lamp would give a larger percentage of its total flux in any solid angle normal to the lamp axis not exceeding $90^{\circ}$. Hence, if the best locations of lamp and screen for measurements of lamps of this type are chosen, they would probably be approximately the best for measurements of lamps of other types also.

From the curves in Figure 9 it is seen that the flux on the screened zones is a minimum for this type of lamp when the lamp is removed 
0.2 of the radius from the center of the sphere, though there is very little choice between this position and any other between the center and $0.4 \mathrm{r}$. Since the total screened area is less at the $0.4 \mathrm{r}$ position, that position would probably be preferable, at least in spheres larger than about $\mathrm{I}$ yard or $\mathrm{I} \mathrm{m}$ in diameter. Other considerations may make desirable a position nearer the center in the smaller spheres, but this must be judged largely by the use to which the sphere is to be put. If the lamp is placed too near the wall, there will be another factor to be reckoned with, namely, absorption of first reflected light by the lamp. The effect of this will be brought out more clearly in the following paragraphs.

\section{ABSORPTION OF LIGHT BY FOREIGN OBJECTS}

If any foreign object is brought into the sphere, it will absorb light and reduce the illumination of the sphere window, even though it is screened from the window.

As before, let

$E_{\mathrm{m}}=$ illumination by reflected light (foot-candles);

$E_{\mathrm{d}}=$ average direct illumination;

$a=$ absorption factor of sphere surface;

$a^{\prime}=$ absorption factor of foreign body in sphere;

$F=$ total light flux from source, in lumens;

$r=$ radius of sphere, in feet;

$b=$ average brightness of sphere wall (candles per square foot) when there is no foreign body in the sphere;

$b^{\prime}=$ average brightness of sphere wall when the foreign body is in the sphere;

$S=$ surface area of foreign body;

$A=$ area of sphere.

As previously stated, the illumination at any point in front of an infinite plane of brightness $b$ is $\pi b$. Also, the flux given off by unit area is $\pi b$ lumens.

If the foreign body is far enough from the walls of the sphere so that it does not reduce the illumination of the walls unequally, and does not receive any direct light from the lamp, it will receive the average illumination $\pi b^{\prime}$ foot candles (since the illuminating surface is equivalent to an infinite plane), and altogether the flux $\pi b^{\prime} S$, of which it will absorb the fraction $\pi b^{\prime} S a^{\prime}$ lumens.

The surface of the sphere radiates the light flux $\pi b^{\prime} A$ lumens and absorbs the fraction $a$ of the total flux received. Hence it receives $\frac{\pi b^{\prime} A}{\mathrm{I}-a}$ and absorbs $a \frac{\pi b^{\prime} A}{\mathrm{I}-a}$ lumens. 
Since all the light is absorbed, the flux absorbed must equal the total flux radiated by the lamp, or

$$
\begin{aligned}
& \pi b^{\prime} S a^{\prime}+\frac{\pi a b^{\prime} A}{\mathrm{I}-a}=F . \\
& b^{\prime}=\frac{F(\mathrm{I}-a)}{\pi S a^{\prime}(\mathrm{I}-a)+\pi a A} .
\end{aligned}
$$

If there is no foreign body in the sphere, then

$$
\begin{gathered}
\frac{\pi a b A}{\mathrm{I}-a} \text { must equal } F, \text { and } \\
b=\frac{F(\mathrm{I}-a)}{\pi a A} .
\end{gathered}
$$

Hence

$$
\bar{b}^{\prime}=\frac{\frac{F(\mathrm{I}-a)}{\pi S a^{\prime}(\mathrm{I}-a)+\pi a A}}{\frac{F(\mathrm{I}-a)}{\pi a A}}=\frac{a A}{S a^{\prime}(\mathrm{I}-a)+a A},
$$

or

$$
b^{\prime}: b=\mathrm{I}: \mathrm{I}+\frac{S a^{\prime}(\mathrm{I}-a)}{a A} .
$$

If the foreign body is brought near the surface of the sphere (the foreign body is assumed to be something other than the lamp in this case), it cuts off some light from the wall approached, and hence its absorption of reflected light is less because the brightness of the wall approached is reduced. If the foreign body is the light source itself, the absorption is increased, because the lamp receives a greater fraction of the first reflected light. The value in (I8) is nearest correct when $a$ and $S$ are small, since in that case the brightness of the sphere wall is most nearly uniform.

The results shown in Table 2, page 296 , apparently indicate that the absorption of reflected light by foreign objects is independent of their shape, which is to be expected from the theory as developed above.

\section{EFFECT OF LAMP POSITION}

In Figure 4, page 298, are given calculated and observed curves showing the reduction of sphere window illumination as the lamp approaches the portion of the wall screened from the observation window. The calculated curves were obtained in the following manner: 
A diagram of the sphere similar to Figure 6 was drawn, and the outline of the screened area, zone 2, was established. By the aid of a protractor the angles at the lamp subtended by the screen and zone 2 were measured, and from the curve in Figure 8 the percentages of the total flux which are incident on the screen and zone 2 were obtained. For example, take the case when the 38 $\mathrm{cm}$ screen is used and the lamp is $76 \mathrm{~cm}$ (30 inches) from the door. Then the angles at the lamp which are subtended by the screen and zone 2 are $27^{\circ}$ and $88^{\circ}$, respectively. Referring to Figure 8 , the flux incident on the screened areas is found to be I8. I per cent of the total delivered by the lamp. Since $a=7.5$ per cent, the illumination of the observation window is shown by equation (6) to be

$$
E^{\prime}=K^{\prime}(\mathrm{I}-\delta a)=K^{\prime}(\mathrm{I}-0 . \mathrm{I} 8 \mathrm{I} \times 0.075)=0.986 K^{\prime},
$$

which is 99.7 per cent of the illumination of the window when the lamp is $99 \mathrm{~cm}$ from the door, or 98.6 per cent of the theoretica value for the illumination of the empty sphere by reflected light only.

If a source giving all its light on the unscreened area is measured in terms of vacuum tungsten standards in this sphere, using the substitution method, the error of measurement to be expected would be given by the curves in Figure 4. For example, if the lamp and reflector were $100 \mathrm{~cm}$ from the sphere door, the error would be plus 0.2 per cent with a $19 \mathrm{~cm}$ screen, and + I.o per cent with a $38 \mathrm{~cm}$ screen. If this were the only factor affecting the accuracy of the results, it would be expected that higher values in terms of such standards would be obtained for an opaque reflector unit as it approached the screened wall, since practically all of the direct light falls on the unscreened area. As a matter of fact, however, measurements of such a unit, evaluated in terms of a standard lamp measured in the same positions, gave constant results at all positions up to about $20 \mathrm{~cm}$ from the sphere wall; that is, the sphere window illumination fell off in about the same proportion with the reflector unit as with the bare lamp. The probable reason for this was that the reflector unit absorbed more and more light as it approached the wall because it received more of the first reflected light from the wall, and the reduction due to this cause happened to be just the same in amount as was to be expected in the case of the bare lamp, where the reduction was due to absorption by the screened areas. It should be noted here 
that a screen of about $19 \mathrm{~cm}$ diameter is large enough for the measurement of all sizes of incandescent lamps in this sphere, and that the $38 \mathrm{~cm}$ screen would be used only in case a lamp of very extensive area was to be measured. Since nearly all other types of incandescent lamps and reflector units throw a still smaller proportion of their total flux on the screened areas in this sphere, the error of measurement due to the screened areas should not exceed 0.3 per cent when a $19 \mathrm{~cm}$ screen and vacuum tungsten standards are used, the lamp being in its normal position, $25 \mathrm{~cm}$ from the sphere center, and it would be as great as this only when measuring a source which threw all its light on the unscreened areas.

In case a lamp which threw all its light on the screened area was measured with the $19 \mathrm{~cm}$ screen, the lamp being at the roo $\mathrm{cm}$ position, the error would be $-(\mathrm{a}-0.3$ per cent $)=-7.2$ per cent. This is an extreme case, however, since in such a measurement the logical method would be to direct the beam toward the unscreened area, when the error would be only +0.3 per cent.

This method of analyzing the operation of a sphere makes possible an estimate of the error which may be encountered in practice with a definite arrangement of sphere screen, lamp socket, etc., and such an analysis would be valuable in considering the accuracy of integration with any particular sphere. It should not be overlooked, however, that differences in absorption of reflected light by the standard and test lamps may cause errors greater than these.

\section{ERROR OF INTEGRATION OF NARROW CONE OF LIGHT}

In the theory of the sphere as developed above, and in all the literature on the subject, the assumption has been made that the sphere surface is a perfect diffuser. Also, it has been assumed that the translucent window is a perfectly diffuse transmitter of light, so that the brightness of the observed side is directly proportional to the illumination of the opposite side, regardless of the angle of incidence of the light contributing to this illumination. These ideal conditions are not realized in practice, and hence it is important to determine the amount of the departures and the error which may occur on account of them.

The illumination of any part of the surface of a sphere surfaced with rough white cement or a matt white paint may be analyzed into three components: (a) The light flux received directly from the lamp; (b) the flux contributed by the first reflection of the 
direct illumination of all other parts of the sphere surface; and $(c)$ the light due to multiple reflections of $(b)$. As previously stated, the part (a) may vary through a very wide range, and hence it is usually screened from the observation window. The surface is nearly enough a perfect diffuser to make the part $(c)$ entirely uniform, and independent of the way in which the direct light is distributed over the sphere surface. Hence the departure from perfect diffuse reflection by the sphere surface may be assumed to affect only the part (b), though lack of perfect diffusion by the window affects both $(b)$ and $(c)$.

Let $A=$ area of sphere;

$F=$ light flux (lumens) radiated by lamp;

$E_{\mathrm{d}}=$ average direct illumination $=\frac{F}{A}$;

$E^{\prime}=$ average illumination by first reflection of $E_{\mathrm{d}}$;

$E=$ total illumination of observation window which is screened from $E_{\mathrm{d}}$.

Neglecting the effect of any direct light on the screened areas, and assuming perfect diffusion,

$$
\begin{aligned}
& E^{\prime}=m E_{\mathrm{d}}=(\mathrm{I}-a) E_{\mathrm{d}} ; \\
& E=\frac{E_{\mathrm{d}}}{a}-E_{\mathrm{d}}=\frac{E_{\mathrm{d}}(\mathrm{I}-a)}{a} .
\end{aligned}
$$

Then

$$
\frac{E^{\prime}}{E}=\frac{E_{\mathrm{d}}(\mathrm{I}-a)}{E_{\mathrm{d}} \frac{(\mathrm{I}-a)}{a}}=a .
$$

In Figure Io are shown experimental curves for the diffusion characteristics of the sphere window and the sphere surface. When a flat disk of the Keene's cement with which the sphere was originally surfaced is illuminated normally, its specific brightness is different at different angles of view.

If the radiated flux is integrated, it is found that at all angles except $50^{\circ}$ from the normal to the surface the brightness of the cement is greater or less than that of a perfect diffuser radiating the same total flux. The percentage deviations at various angles are shown by curve $A$ in Figure ro. The curve for the zinc oxide paint described in Part I of this paper is practically the same as curve $A$ for all angles from $15^{\circ}$ to $75^{\circ}$. It is about 5 per cent higher than curve $A$ at $5^{\circ}$ and 5 per cent lower at $80^{\circ}$.

If the window were a perfect diffuser, its brightness measured normally should vary as the cosine of the angle of incidence of 
the light on the opposite side (angles being measured from the normal). Curve $B$ shows the deviation of a milk-glass window, surfaced with coarse carborundum (No. 60), from the cosine law of transmission.

If a photometer is standardized to measure the normal illumination on the face of this milk glass opposite to the side viewed, calculations show that if the window was illuminated by a uniformly bright infinite plane the evaluation of the illumination would

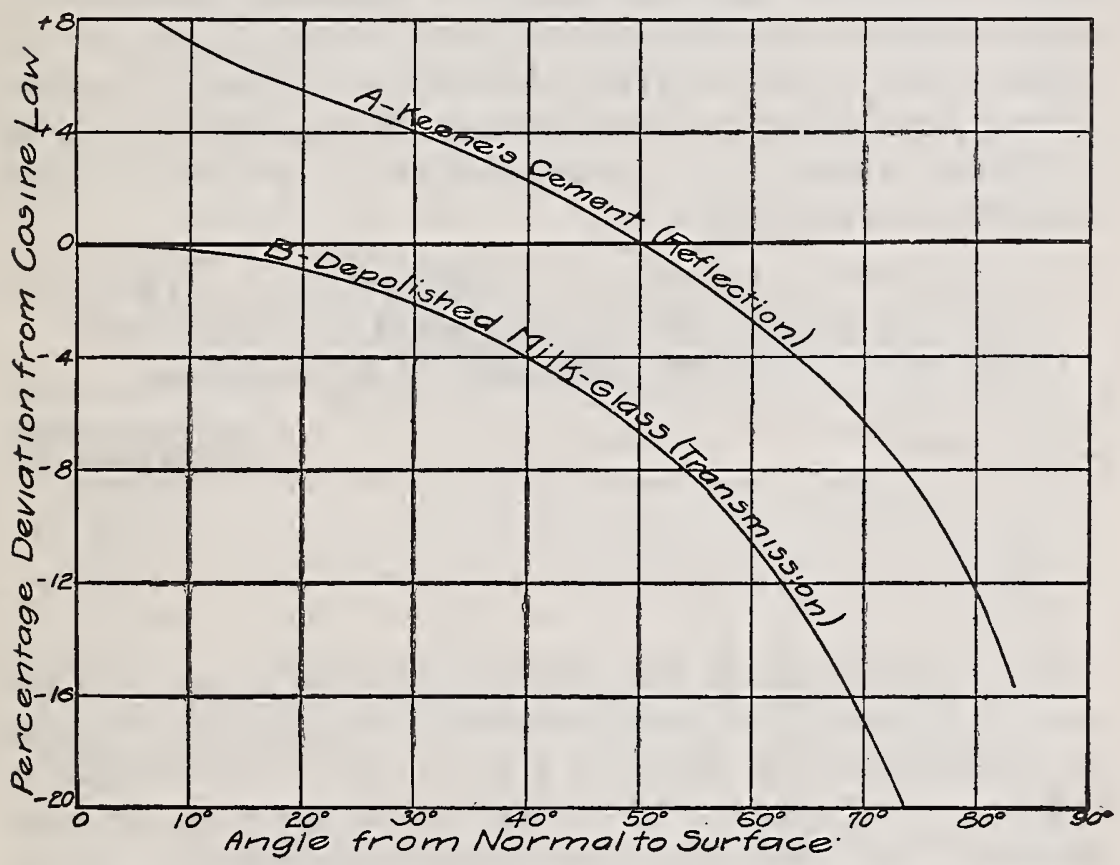

FIG. Io.-Diffusion characteristics of Keene's cement and depolished milk-glass

be too low by 7.6 per cent. This is practically the condition in the sphere as regards the portion (c) defined above. If the sphere surface is illuminated normally to a uniform amount, as would be the case if a point source of light was placed at the center of the sphere, the illumination due to the first reflected flux, not perfectly diffused (see curve $A$ ), would be evaluated too low by 8.8 per cent. Hence, since the absorption factor of this sphere is now 6.0 per cent, and since that also represents the ratio of $E^{\prime}$ to $E$ (see above), the error in the measured value of the window illumination would be

$$
\begin{aligned}
e^{\gamma}=0.94(-0.076)+0.06 & (-0.088)=-0.07 \mathrm{I}_{4}-0.0053=-0.0767 \\
& =-7.7 \text { per cent } .
\end{aligned}
$$


If the direct light is incident as a very narrow cone, the error of measurement of the first reflected flux depends on the relative positions of the illuminated spot and the window (assuming that the direct light is incident normally to the surface). The error of measurement of the diffusely reflected light from reflections after the first, which is $0.94 \times 0.076=7.14$ per cent, would remain the same. If the angle of incidence of this first reflected light on the window is $\theta$, the angle of emission from the sphere surface is also $\theta$. Referring again to Figure Io, the error of measurement of the first reflected light is the product of the algebraic sum of the deviations there shown by curves $A$ and $B$ for the particular angle considered into the absorption factor of the sphere surface. For example, if $\theta=45^{\circ}, \mathrm{e}^{\prime \prime}$, the error of measurement, would be

$\mathrm{e}^{\prime \prime}=6.0$ per cent $(+\mathrm{I} .3$ per cent -5.3 per cent $)=-0.25$ per cent;

$\therefore$ the total error would be $-7.14-0.25=-7.39$ per cent.

Other values have been calculated to be as follows:

$\theta$, angle of incidence

Error of measurement of window illumination*

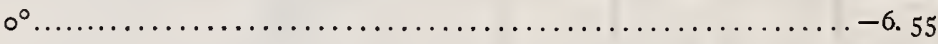
Per cent.

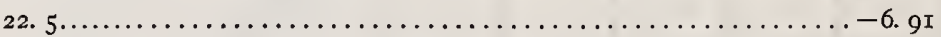

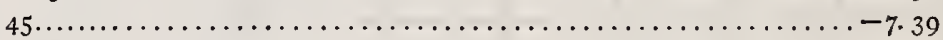

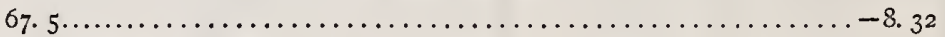

The absolute value of this error is immaterial in the ordinary use of the sphere. The important point is the agreement between the evaluation of the flux from a lamp when the direct light is uniformly distributed over the sphere surface and when the same amount of flux is concentrated in a narrow beam of light. It has been shown above that when the direct light is uniformly distributed the error in evaluating the illumination of the window in this sphere should be -7.7 per cent. If the narrow cone of light is directed at a point $90^{\circ}$ from the window-that is, $\theta=45^{\circ}$, the error of measurement would be only about 0.3 per cent less than the error made in integrating a point source radiating the same amount of flux-and this difference is the error made in evaluating a point source in terms of a narrow cone incident at a point $90^{\circ}$ from the observation window.

*Assuming no direct flux on screened areas. 
8. FACTORS AFFECTING THE ACCURACY OF MEASUREMENT

From equation (7) it is evident that increased accuracy may be obtained by reducing $a$, the absorption factor, or decreasing $\delta$, the proportion of light on the screened area. This is accomplished by making the screen as small as possible and placing it in the position to make the screened area a minimum. Equation (I8) shows that the influence of the presence of a foreign body may be decreased by making $a$, the absorption factor of the sphere, large, or by making the relative areas of foreign body and sphere surface small. Hence it is seen that in both cases the accuracy of integration is increased by making the sphere area large, assuming that no correction for the presence of the foreign body is to be made. This is ordinarily the case when incandescent lamps being life tested are to be photometered.

The action of the absorption factor is opposite in the two cases, however, since in the former a small factor is best, whereas in the latter a large factor reduces the influence of the foreign body, and hence reduces the error of neasurement if no correction is made. In certain kinds of routine measurements, for example, the measurement of arc lamps, the effect of the presence of the lamp mechanism is easily corrected for by the method of measurement. This is not so easily done in the case of life test measurements of incandescent lamps, however, since the lamps may be of various sizes and degrees of blackening, and the measurement of the influence of each individual lamp in the sphere would involve a prohibitive amount of labor. On the other hand, if the absorption factor of the sphere walls is very low, this effect may cause appreciable errors if neglected.

In a particular case here, one life test lamp, a Iooo-watt type C Mazda which had fallen to about 20 per cent of its initial candlepower, reduced the sphere window illumination 8 per cent when it was introduced unlighted into the sphere. By calculation, using equation (I8), it is found that the reduction of window illumination would have been 9.2 per cent for a sphere absorption factor of 6 per cent and 2.7 per cent for an absorption factor of 20 per cent. This lamp presented an extreme case, but it is not at allimprobable that lamps showing one-fifth of this degree of blackening would be frequently encountered. 


\section{BEST CONDITIOIN OF SPHERE FOR CERTAIN WORK}

In the case where a sphere is to be used for work such as life test measurements, or other work where determination of the allowance for absorption by the lamp would necessitate more labor than could reasonably be expended on the measurement, a sphere paint having a reflection factor of about 80 per cent would give better results than a highly reflecting paint, and the influence of the presence of the foreign body could usually be neglected in spheres about 6 feet and larger in diameter.

When a sphere is to be used most of the time for standardization work, it would be best to select a high reflecting power paint, and make allowance for the influence of the presence of the lamp, if measurable.

\section{CLASSIFICATION OF BIBLIOGRAPHY}

In order to assist in the examination of the articles listed in the following bibliography, a general summary of the subjects discussed in them has been prepared. The general classification is as follows:

(a) Mirror integrators: I to 6, 25 .

(b) Box integrators: $26,28,34$.

(c) Theory of the Ulbricht sphere: 7 to Io, I4, I5, I9, 24, 25, 27, 29, 31, 36, 38, 39, 40.

(d) Details of sphere construction: 8, 9, I0, I2, I3, I7, I8, I9, $2 \mathrm{I}, 24,3 \mathrm{O}, 32,35,36$.

(e) Methods of measurement of spherical candlepower: 9, Io, I2, I3, I $8,21,24,29,3$ I, 35, 36 .

(f) Theory of hemispherical candlepower measurements: 9, II, I 4, I 5 .

(g) Methods of measuring hemispherical candlepower: 15, 19, 20.

(h) Special tests of and with integrating spheres: 8, 9, IO, I2, I3, I 5, 2I, 23, 29, 3I, 35, 36, 37, 38, 39, 4 O.

\section{BIBLIOGRAPHY}

I. Blondel, $\mathrm{La}$ détermination de 1 'intensité moyenne sphérique des sources de lumière, L'Éclair. Élect., 2, p. 385, I895; 3, p. $57,406,538,583$, I895; C. R., 120, p. 3 II, 550, I895.

2. Blondel, Mesure directe de l'intensité lumineuse moyenne sphérique, L'Éclair. Élect., 8, p. 49; 1896 .

3. C. P. Matthews, An improved apparatus for arc-light photometry, Trans. A. I. E. E., 18, p. 67I, I90I; 20, p. 59, I902; L’Éclair. Élect., 40, p. I28, I904; J. Inst. Elec. Engr., 32, p. 63I, 1903.

4. Blondel, Les integrateurs photométriques, mesophotomètres et lumenmètres, Bull. Société Internationale des Électriciens, 4, p. 659, I904; L'Éclair. Élect., 42, p. 66, I905; Sci. Abst. B, 8, abst. 487 and I689, I905. 
5. E. P. Hyde, On the theory of the Matthews and the Russell-Leonard photometers for the measurement of mean spherical and mean hemispherical intensities. B. S. Bulletin 1, I905 (or B. S. Sci. Papers, No. 12).

6. G. H. Stickney and S. L. E. Rose, Photometry of large light sources, Trans. I. E. S., 6, p. 64I; I9II.

7. Sumpner, The diffusion of light, Phil. Mag., 35, p. 81; I893.

8. R. Ulbricht, Die bestimmung der mittleren räumlichen lichtintensität durch nur eine messung, ETZ, 21, p. 595, I900; Sci. Abst., 3, abst. 2 I 54, I 900.

9. Ulbricht, Die vorange im kugelphotometer, ETZ, 26, p. 512, I905; Sci. Abst., 8 , abst. I 60 , I905.

I0. I. Bloch, Das kugelphotometer in theorie und praxis, ETZ, 26, p. I047, I074, I905; Illuminating Engineer (New York), 1, p. 42I, I906; Sci. Abst., 8, abst. I688, I905.

II. Ulbricht, Die hemisphärische lichtintensität und das kugelphotometer, ETZ, 27, p. 50, I906; L’Éclair. Élect., 46, p. 432, I906; Sci. Abst., 9, abst. 370, Ig06.

I2. M. Corsepius, Eine ausfuhrungsform des Ulbrichtschen kugelphotometers, ETZ, 27, p. 468, 1906; Illuminating Engineer (New York), 1, p. 482, I906; Sci. Abst., 9, abst. 772, I906.

13. B. Monasch, Versuche mit hilfsapparaten zur bestimmung der mittleren sphärischen und der mittleren hemisphärischen lichtstärke, ETZ, 27, p. 669, 695, 803, I 906; Illuminating Engineer (New York), 1, p. 586, 700, I906; Sci. Abst., 9, abst. I 233, I 906.

14. E. Presser, Die theorie der Ulbrichtschen kugel, Elektrotechnischer Anzeiger, p. 885,912, I 906 .

I5. Ulbricht, Zur anwendung des kugelphotometers, ETZ, 28, p. 777, I907; Electrical World, 50, p. 418, I907; Sci. Abst., 10, abst. I086, I907.

16. Schweizerische Elektrotechnische Zs., 4, p. 85, 97, I I0, I907; Sci. Abst., 10, abst. 437 , I907.

17. Modern photometrical appliances, Illum. Engr. (London), 1, p. 228; I908.

I8. L. Bloch, The globe photometer in practical photometry, Illum. Engr. (London), 1, p. 274; 1908 .

Ig. On the theory of the globe photometer, Illum. Engr. (Iondon), 1, p. 553; Igo8.

20. M. Corsepius, The measurement of the mean hemispherical candlepower by the aid of the Ulbricht globe photometer, Illum. Engr. (London), 1, p. 80r, 895; Ig08.

21. Sharp and Millar, The integrating sphere in industrial photometry, Trans. I. E. S., 3, p. 502, I908; Illum. Engr. (London), 1, p. I03 I, I908.

22. Ulbricht, Zur lichtschwerpunkt-bestimmung, ETZ, 30, p. 322, I909; Sci. Abst., 12, abst. 490, r 909 .

23. A. A. Perrine, Experimental study of the globe photometer, Electrical World, 54, p. 727 ; 1909 .

24. E. Winkler-Buscher, Die Ulbrichtsche kugel zur bestimmung der mittleren sphärischen bezw. der mittleren hemisphärischen lichtstärke, Elektrotechnik und Machinenbau, 28, p. 659, I910; Sci. Abst., 14, abst. I20, I9I I.

25. The determination of mean spherical candlepower (by an engineering correspondent), Illum. Engr. (London), 3, p. 31, 265, I9io.

26. W. E. Sumpner, The direct measurement of the total light emitted from a lamp, Illum. Engr. (London), 3, p. 323, I9Io; Discussion, p. 387; Electrician (London), 65, p. 72, I 910 .

27. E. B. Rosa, Photometric units and nomenclature, B. S. Bulletin, 6, IgIo (or B. S. Sci. Papers, No. I4I).

28. L. W. Wild, The box integrating photometer, Illum. Engr. (London), 3, p. 549; IgIo. 
29. E. Dyhr, Nachtrage zur theorie des kugelphotometers, ETZ, 31, p. I295, I910; Sci. Abst., 14, abst. I28, I9I1.

3०. E. W. Marchant, Globe photometer, Illum. Engr. (London), 4, p. 37; rgr I.

3r. Chaney and Clark, Notes on the integrating sphere and arc lamp photometry, Trans. I. E. S., 10, p. I; I9I5.

32. Integrating sphere equipped for testing gas-filled lamps, Electrical World, 65, p. 120 ; 1915 .

33. A. Utzinger, Innenanstrich für die Ulbrichtsche kugel, ETZ, 36, p. I37, I9I5; Sci. Abst., 18, abst. 724, 1915.

34. L. O. Grondah1, A. box photometer, Trans. I. E. S., 11, p. I52; 1916.

35. E. B. Rosa and A. H. Taylor, The integrating photometric sphere, its construction and use, Sci. Abst., B, 19, abst. 572, 1916; Trans. I. E. S., 11, p. 453, Igr6.

36. F. A. Benford, Jr., The integrating sphere and a new type of compensating screen, Trans. I. E. S., 11, p. 997 ; 1916.

37. Henry A. Gardner, The light-reflecting values of white and colored paints, J. Franklin Inst., 181, p. 99; 19r6.

38. F. A. Benford, An integrating hemisphere, Trans. I. E. S., 13, p. 323 ; 1918.

39. F. A. Benford, A universal photometric integrator, Trans. I. E. S., 15, p. I9; I920.

40. A. H. Taylor, Measurement of diffuse reflection factors, and a new absolute reflectometer, B. S. Sci. Papers No. 39I; J. Optical Soc. of America, 4, p. 9, rg20.

41. P. G. Nutting, A new method and an instrument for determining the reflecting power of opaque bodies, Trans. I. E. S., 7, p. 412; 1912.

42. Geo. W. Middlekauff, A new form of direct-reading candlepower scale and recording device for precision photometers, B. S. Bulletin, 7, p. II; IgII (or B. S. Sci. Papers No. I44).

43. A. P. Trotter, Diffused reflexion and transmission of light, Illum. Engr. (London), 12, p. 243; I919.

44. A. H. Taylor, A simple portable instrument for the absolute measurement of reflection and transmission factors, B. S. Sci. Papers No. 405; Trans. I. E. S., 15, p. 8II, I920.

The following references have been added since the original manuscript was prepared. None of these have been consulted in the preparation of the paper.

A spherical photometer, Electrician, 57, p. 1057; 1906.

Pressner, Ulbricht sphere, Electrical World, 49, p. 806, I907; Elektrotechnischer Anzeiger, March 3, 1907.

W. Haensch, Die kugelbeleuchtungsapparate und ihre vielseitige verwendung, Deut. Mech. Zs., 1914, p. I.

N. A. Halbertsma, Die werkung der ringblende vor de milchglasscheibe der Ulbrichtschen kugel, Zs. f. Beleuchtungswesen, 22, p. 43; IgI6.

The use of the sphere photometer in street lighting tests, (editorial), Electrical Review and Western Electrician, 69, p. 93; I916.

Blondel, Zs. f. Beleuchtungswesen, April 30, Ig06; Electrical World, 47, p. Ir53, Ig06. H. Krüss, Integrating photometer, J. f. Gasbeleuchtung., 51, I908; Electrical World, 52, p. 307, 1908 .

A. Blondel, Blondel-Krïss integrating photometer, Illum. Engr. (London), 2, p. 785; Ig09.

An improved spherical photometer, Electrical World, 48, p. 23; 1906.

R. von Voss, Ein neues kugelphotometer für betriebsmessung an gluhlampen, ETZ, 38, p. I88; I917. 
Un nouveau photomètre sphérique pour lampes à incandescence, Rev. Gén. de l'Élect. 2, p. 807 ; 1917.

R. von Voss, Siemens and Halske globe photometer, ETZ, 38, p. 605, I9I7; Sci. Abst. B, 21, abst. 2 I9, I9I8.

R. von Voss, A new globe photometer for incandescent lamps, Electrician, 80, p. 630,$1918 ; 81$, p. 418 , I9I8.

Sphere pour la détermination des angles solides des flux lumineux, Rev. Gén. de l'Élec., 5, p. I54 D; I9I9.

F. E. Cady, Note on the effect of lack of whiteness in the paint and window of an Ulbricht sphere, J. Franklin Inst., 189, p. 787 , 1920; Electrical World, 77, p. 368, Ig2I.

F. A. Benford, A universal photometric integrator, Trans. I. E. S., 15, p. I9; 1920.

A. H. Taylor, A new portable reflectometer, Electrical World, 76, p. 467; I920.

$\mathrm{H}$. Buckley, The whitened cube as a precision integrating photometer, J. Inst. Elec. Engr. (London), 59, p. I43; I921.

C. H. Sharp and W. F. Little, Measurement of reflection-factor, Trans. I. E. S., 15, p. $802 ; 1920$.

E. Karrer, The use of the Ulbricht sphere in measuring reflection and transmission factors, B. S. Sci. Papers No. 415; J. Optical Soc. of America, 5, p. 96, I92 I.

Von R. Ulbricht, Das kugelphotometer, published by R. Oldenbourg, München und Berlin; r920.

WASHINGTON, September 26, I92 I. 



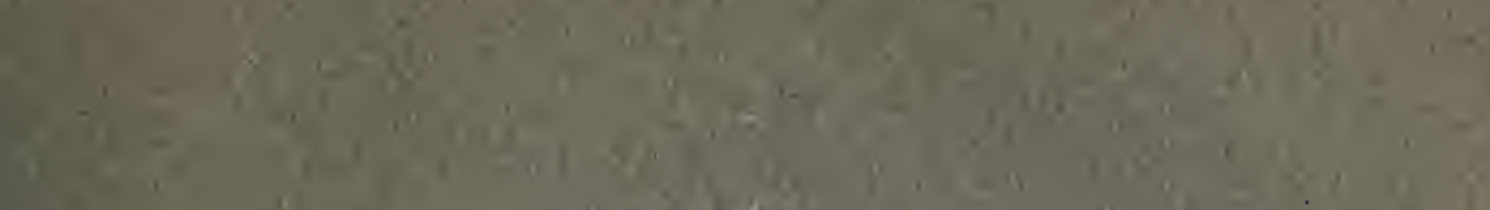
(3)

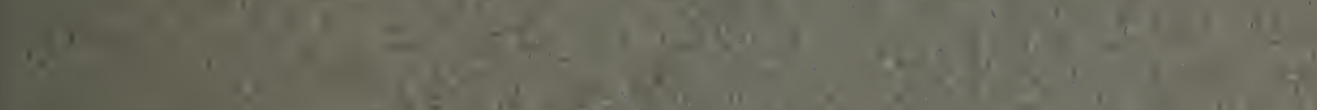

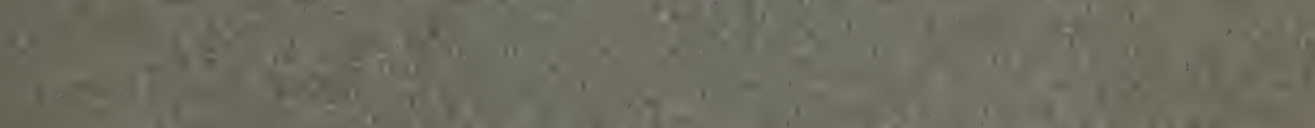

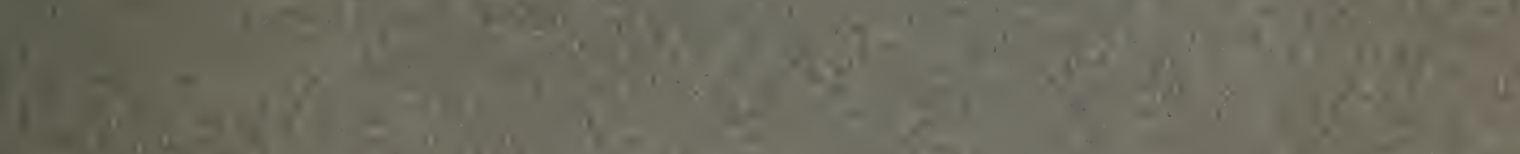

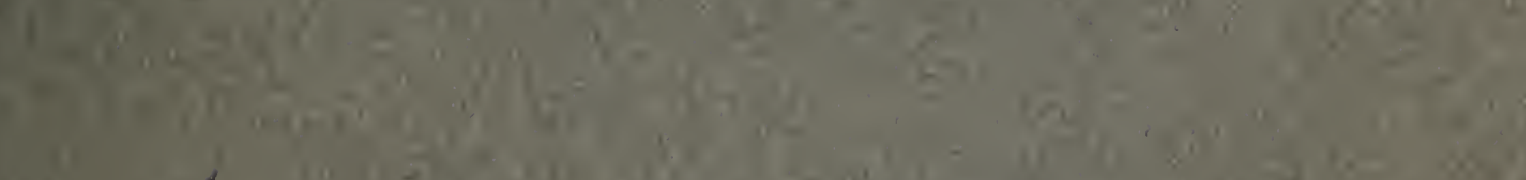

ing

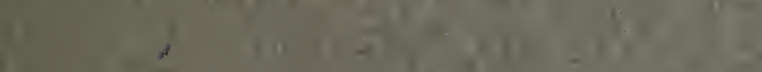

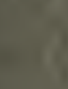

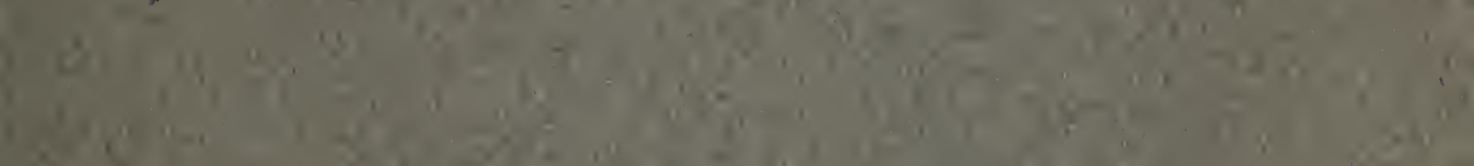

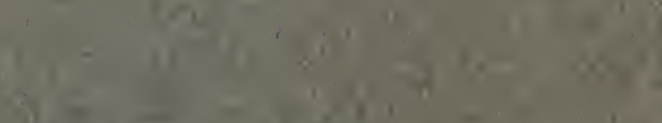

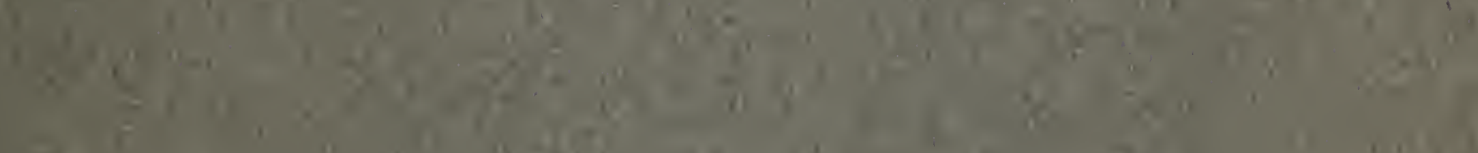

L

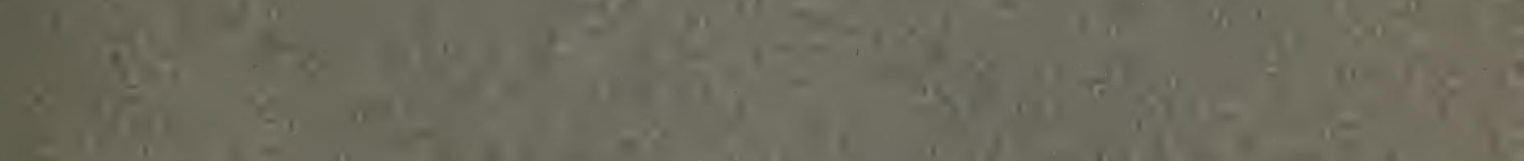

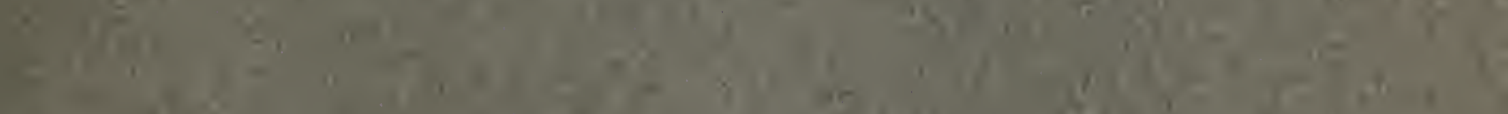

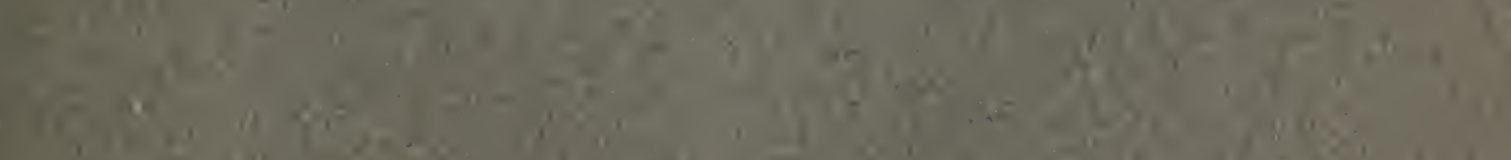

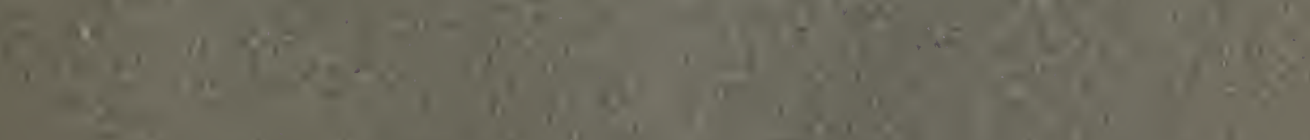
1 
